\title{
Tomato tolerance to abiotic stress: a review of most often engineered target sequences
}

\author{
Aneta Gerszberg ${ }^{1}$ Katarzyna Hnatuszko-Konka ${ }^{1}$
}

Received: 6 September 2016 / Accepted: 12 January 2017 / Published online: 27 January 2017

(C) The Author(s) 2017. This article is published with open access at Springerlink.com

\begin{abstract}
Tomato is one of the most often cultivated vegetable species worldwide. Due to the anti-oxidative and anti-cancer properties of lycopene, tomato consumption as well as production is still increasing. However, its productivity is impaired by a wide range of abiotic stresses, and the establishment of stress-tolerant crops is a key challenge for agricultural biotechnology. Until now, a few genetic approaches have been used to achieve stress tolerance in cultivated tomato plants. Such achievements are based on current knowledge concerning plant adaptation. The presence of adverse environmental factors like extreme temperatures, salinity or drought cause definite biochemical and physiological consequences. Mostly, these are the changes in the metabolic pathways, the expression of stress-inducible genes or the accumulation of low-molecular compounds that play a crucial role in maintaining the plasticity of reactions. The biotechnological methods used to modify tomato to produce "upgraded" plants are based on introgression of several genes coding enzymes known to mitigate stress or genes contributing to signalling and diverse regulatory pathways. Here, we present an overview of the most often chosen target sequences/molecules that are genetically delivered or engineered to obtain tolerance to environmental constraints. Since adverse conditions cause interrelated stress responses, it is the tolerance molecular players that
\end{abstract}

Aneta Gerszberg

angersz@biol.uni.lodz.pl

Katarzyna Hnatuszko-Konka

kath@biol.uni.lodz.pl

1 Department of Genetics, Plant Molecular Biology and Biotechnology, Faculty of Biology and Environmental Protection, University of Lodz, Banacha 12/16, 90-237 Lodz, Poland are consecutively presented in this paper rather than the typically reviewed division of stress types.

Keywords Tomato $\cdot$ Abiotic stress $\cdot$ Tomato transformation

\section{Introduction}

Tomato (Solanum lycopersicum L.) is a popular and economically important crop plants around the world. It contains a valuable compound, lycopene, which possesses anti-oxidative and anticancer properties. Therefore, tomato production and consumption are permanently increasing (Raiola et al. 2014). In 2013 tomato was 7th in global production, achieving a world production of approximately $164,000,000.00$ million tonnes on a total area of nearly 4.8 million hectares (FAOSTAT 2013). Being a tropical plant, tomato is well adapted to almost all climatic regions of the world; however, environmental stress factors are the primary constraints of this crop's yield potential. Recently, the molecular pathways underlying environmental stress tolerance have been studied intensely with much emphasis on the tolerance mechanisms pertaining to individual stresses. Abiotic stress is a general term, which includes miscellaneous stresses e.g. chilling, high temperature, osmotic shock, drought, salinity, water logging, wounding, exposure to ozone, toxic ions, excessive light and UV-B irradiation (Rehem et al. 2012). Unfortunately, abiotic stresses are complex in their nature and controlled by networks of different factors (e.g. genetic and environmental) that impede crop plant breeding strategies (Da Silva and de Oliveira 2014).

While traditional approaches achieve their limit, current agriculture must deploy quite novel solutions to meet the 
demands of the world's population. Genetic engineering is one of the many tools available for creating improved, modern crop plants. Recently, technological advances in functional genomics have been made and they have helped to reveal the numerous gene families and processes, that alter adaptation to abiotic stresses and thereby improve yield. Since in most cases plants have windows of tolerance to surrounding environmental factors, genetic engineering can be used to enhance the native adaptation abilities. Genes can be placed into various of expression cassettes, and subsequently introduced to plants in which they do not naturally occur. Genetically engineered plants can be employed not only as origin of novel cultivars, but can also be helpful in analysing and describing the activity and interplay of gene networks for abiotic stress tolerance (Kissoudis et al. 2015). Given the complexity of stress and its genesis, it is rare to meet a single abiotic stress in nature. A great number of stress-responsive pathways and components is common in reactions to multiple stressors. Consequently, instead of the typically reviewed division of stress types, we decided to provide a general overview of the molecular background i.e. genes, proteins and other molecular compounds, that are considered to be significant for plant function and response under stress conditions. Its components are perceived as targets in "the gene therapy" of plants in stress. We present some results of such an approach hoping it will allow the readers to get acquainted with the most often engineered target sequences.

\section{Physiological basis of abiotic stress tolerance in plants}

The concept of stress assumes the occurrence of an external factor that disadvantageously influences a plant. It can also be understood as a negative deviation of the living conditions that are optimal for a plant. Hence, tolerance must presume certain plasticity in metabolic reactions that let a plant function in an unfavourable environment (to avoid, tolerate or recover from the stress conditions). This ability to limit the damage triggered by a given stress may be defined as plant tolerance. Adaptation of plants to abiotic stresses is a complex process, that is characterized by activation of multifarious responses engaging composite gene interplay and 'crosstalk' among many molecular pathways (Da Silva and de Oliveira 2014). These complex cellular responses were explained by advancements made in investigating and comprehension of plant abiotic responses at different levels. In general, three stages are distinguished during abiotic stress: (1) the stage of alarm; (2) the stage of resistance; and (3) the stage of exhaustion (Rehem et al. 2012). However, Lichtenthaler (1988) added the fourth stage - the regeneration stage. This particular stage appears exclusively when the stress factor is eliminated before failure becomes too drastic and enables full or partial recovery of the plant's physiological function. At the beginning, any abiotic stress response is the perception of stress signals by cell wall receptors, that activate different signal transduction events involving different intermediate stress genes (Da Silva and de Oliveira 2014). These genes could be members of the mitogen-activated protein kinase cascade, or calcium dependent protein kinase cascade and activate cis-acting elements and transcription factors (TFs) that control expression patterns of stress-response genes. This leads to plant stress tolerance (Fig. 1). Among stress-induced genes three categories can be distinguished: the first category includes genes encoding proteins with known functions (structural or enzymatic), the second category contains transcription factors and regulatory proteins and the third comprises proteins with unknown functions (Yamaguchi-Shinozaki and Shinozaki 2009).

\section{Biotechnological strategies}

Plant in vitro tissue culture techniques have become a prerequisite step to further development of plant transformation methods. Furthermore, advances in plant genetic transformation significantly facilitated progress in the recognition of individual genes and enzymes involved in plant tolerance to various abiotic stresses. Additionally, the advancement of knowledge in the field of genomics of tomato's wild relative species can be exploited in a breeding programs for the introgression of abiotic stress tolerance into common, cultivated tomato cultivars (Foolad 2007; Labate and Robertson 2012).

\section{Methodology of tomato transformation}

Over the past two decades, numerous techniques were used to introduce foreign genes into both mono- and dicotyledonous plants, such as rice, potato, soya bean, tomato or common bean (Sahoo et al. 2011; Gerszberg et al. 2012; Hnatuszko-Konka et al. 2014). The first protocol for the genetic transformation of Solanum lycopersicum was reported in the 1980s and since then a significant progress in this field has been made (McCormick et al. 1986). The tested approaches included both direct methods and those using bacterial vectors, differing in transformed target genome (plastid, nuclear) or in the stability of the transformation.

Mostly, Agrobacterium-mediated transformation procedures for various tomato cultivars have been expanded (Gerszberg et al. 2015). The agroinfection process is complex, and its efficiency depends on a broad spectrum of elements including the presence of a chemoattractant in 
Fig. 1 The plant response to abiotic stress. Primary stresses are interrelated and provoke cellular damage as well as secondary stresses. The initial stress signal cause activation of signalling process as well as transcription control. Consequence of this, is initiation of stress-responsive mechanism to restoration of cellular homeostasis, accompanied by the protection and repair damaged proteins and membranes. Finally, plant gained tolerance or resistance to stress. $A B F$ ABRE-binding factor, Athk 1 Arabidopsis thaliana histidine kinase-1, $b Z I P$ basic leucine zipper transcription factor, $C B F /$ $D R E B$ C-repeat-binding factor/ dehydratation-responsive binding protein, $C D P K$ calciumdependent protein kinase, $C O R$ cold-responsive protein, $H s p$ heat shock protein, $L E A$ late embryogenesis abundant, $M A P$ mitogen-activated protein; $P L D$ phospholipase D - PtdOH, phosphatidic acid, $P X$ peroxidase, $R O S$ reactive oxygen species, $S O D$ super dismutase, $S P 1$ stable protein 1
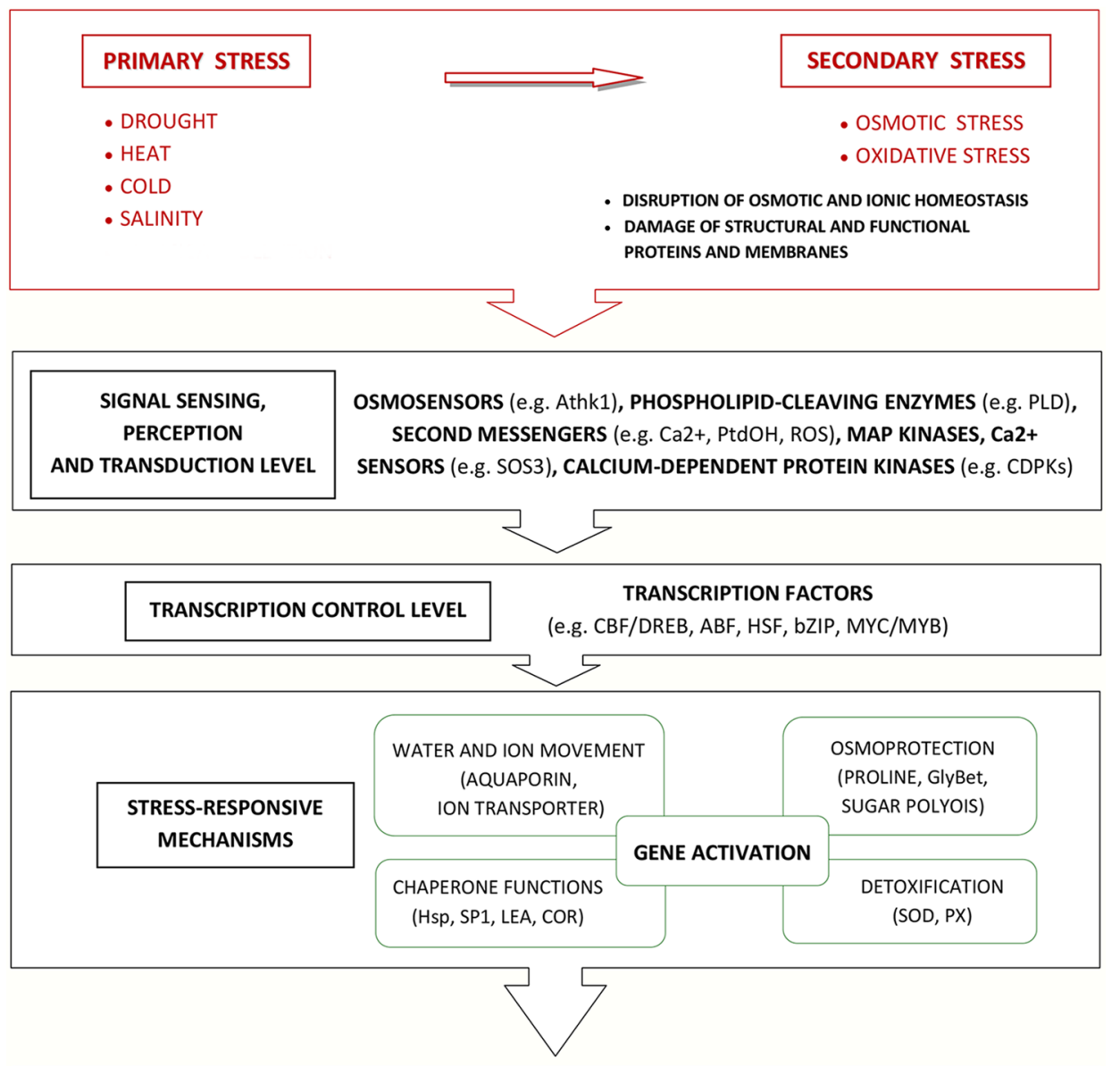

STRESS TOLERANCE

OR

STRESS RESISTANCE
RE-ESTABLISHMENT OF CELLULAR HOMEOSTASIS PROTEINS/MEMBRANES PROTECTION the culture or preculture media, the application of nurse cells, bacterial factors (culture density, virulence of the Agrobacterium strain), the type of plasmid vector and the tissue specific factors (the type of explants and the genotype), the composition of the culture media (concentration of phytohormones), the concentration and kind of selective agents and the cocultivation time (Guo et al. 2012; Chetty et al. 2013; Shah et al. 2015; Sun et al. 2015). Examples of optimisation of aforementioned parameters for tomato transformation are presented in Table 1. Despite numerous attempts to improve transformation protocols with regards to effectiveness, progress in this area is limited due to genotype specificity. Notwithstanding this fact, some efforts to determine an effective genetic transformation method for such "stubborn" cultivars were made (Fuentes et al. 2008). Agroinfection-mediated modifications utilized both Agrobacterium tumefaciens and A. rhizogenes species. Usually, Agrobacterium tumefaciens is the vector of choice for plant transformation. Also, in the case of Solanum lycopersicum engineering, it was harnessed to produce transgenic plants (Hasan et al. 2008; Chetty et al. 2013). Yasmeen et al. (2009) evaluated fruit maturity, gene construct type and in planta technique (fruit injection and floral dip) for the establishment of the optimal protocol of transformation. A higher transformation percentage was obtained for mature fruits (ca. 15-20 times higher) in comparison to immature fruits. To reduce the time of obtaining transgenic plants as well as cases of somaclonal variation, in planta methods were assessed. Yasmeen et al. (2009) tested the floral dip procedure for the flower transformation before and after pollination. The results were interesting and clearly indicated that type of construct and floral stadium are important for transformation effectiveness. A higher efficacy of transformation was reported in the case of flowers treated with a bacterial suspension before pollination. Despite promising transformation efficiency, some adverse changes in the morphology (short and not erected steam, curled leaves) of the plants were observed in comparison 


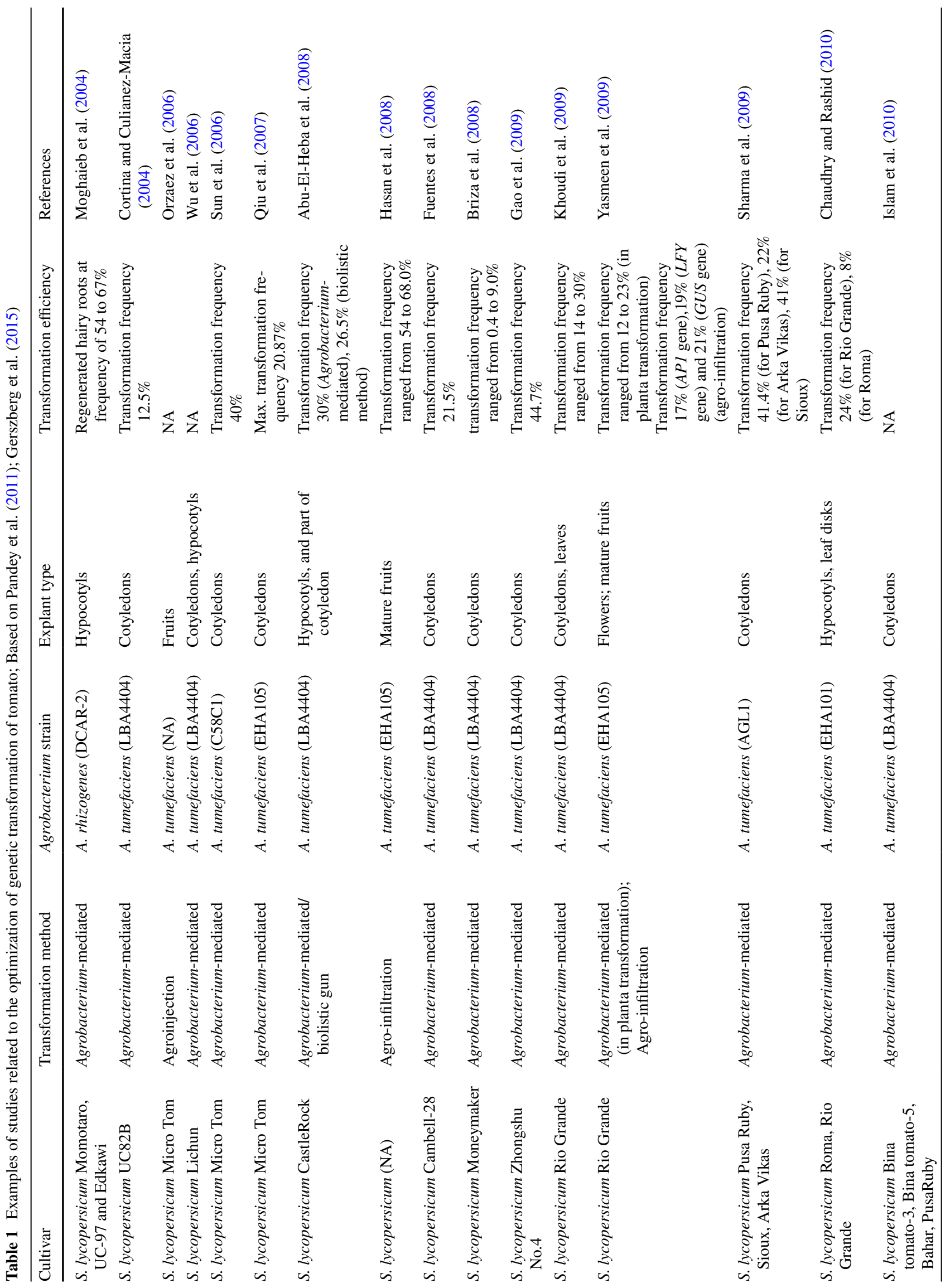




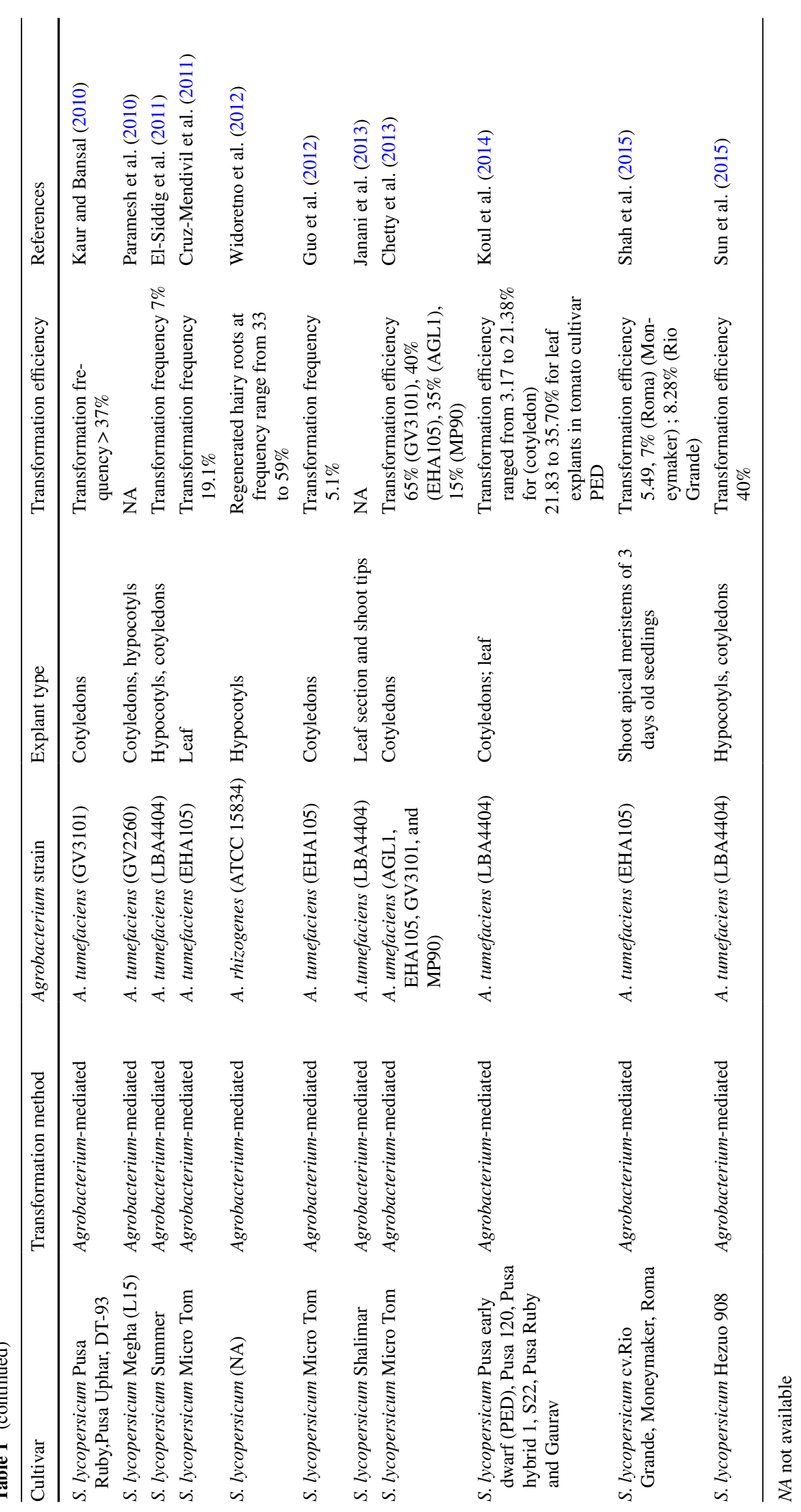


to wild-type (WT) plants. Although the flowers on these plants appeared earlier and were normal, unfortunately they were sterile and did not give fruits (Yasmeen et al. 2009). So far, this methodology has not been broadly employed in tomato transformation. However, Safdar and Mirza (2014) performed a comparison of transformation through tissue culture and in planta transformation using an in vitro fruit injection method and in vivo fruit and flower injection. The results clearly showed superiority of the in vitro fruit injection method in comparison to conventional methods. Recently, Shah et al. (2015) successfully employed an in planta method to obtain cold resistant tomato. Optimization of the transformation parameters allowed to obtain transformation efficiency of about $8 \%$.

Tomato engineering via $A$. rhizogenes was reported by Widoretno et al. (2012) and regeneration of transgenic tomato plants from hairy roots by Peres et al. (2001) and Moghaieb et al. (2004). As the results showed, regeneration from hairy roots was possible; however, the considerable differences in morphogenic responses were revealed. Hairy root-originated plants were characterized by creased leaves, shortened internodes, plentiful root system; they produced flowers (Peres et al. 2001) and fruits with a reduced number of seeds (Moghaieb et al. 2004). Hairy root culture appeared as an alternative system for producing biopharmaceutical compounds in tomato plants. De Guzman et al. (2011) achieved production of the Escherichia coli B-subunit heat labile toxin antigen in tomato hairy root cultures (approximately $10 \mu \mathrm{g} / \mathrm{g}$ blotted weight, BW). Unfortunately, numerous attempts to obtain regenerated plants from hairy root cultures were unsuccessful.

In addition to the aforementioned methods, the particle bombardment method was also used for tomato transformation (Cueno et al. 2010). Ruma et al. (2009) performed experiments to equalize crucial factors (e.g. firing distance, quantity of DNA, concentration of osmoticum, pre-bombardment and post-bombardment culture periods) which resulted in significant transformation efficiency in different tomato explants.

The particle bombardment approach was also used in the elaboration of stable genetic transformation methodology of tomato plastids that seemed to be a crucial step in the transformation of tomato (Ruf and Bock 2014). This recently established transformation technology enabled investigation aiming at improvement of the nutrient content in tomato (e.g. vitamin A, $\beta$-xanthophylls) (Apel and Bock 2009; D'Ambrosio et al. 2011), as well as biopharmaceutical production (e.g. HIV antigens p24) (Zhou et al. 2008).

While several protocols for stable transformation of tomato plants have been recently developed (Hasan et al. 2008; Sharma et al. 2009; Koul et al. 2014), there is still lack of reliable and effective procedure to help with the functional analysis of transgene. To cope with this problem, scientists have recruited transient transformation methodologies. Such an approach can assure fast implementation of the functional analysis of the genes of interest (GOI) (Wróblewski et al. 2005; Fernandez et al. 2009). Fundamental progress in rapid reverse genetics was accomplished by employing RNAi (RNA interference) strategy (Orzaez and Granell 2009; Fernandez-Moreno et al. 2013). In plants, RNAi can be induced in two ways: by a transgene (TIGS, transgene induced gene silencing) or a virus (VIGS, virus-induced gene silencing). The first approach was used for instance to silence gene visl (viscosity) in tomato fruit to obtain transgenic lines with delayed ripening under heat stress (Metwali et al. 2015). Since VIGS represents a useful tool for the identification of gene function, in the other approach different types of viruses (e.g. TRV, Tobacco Rattle Virus) were successfully used as the VIGS vectors and, among them, the TRV vector gave the most robust results in terms of ease of application, efficiency, and absence of disease symptoms (Jaberolansar et al. 2010; Romero et al. 2011; Wang et al. 2015). Moreover, Wang et al. (2015) demonstrated that this technology enabled achieving up to $100 \%$ VIGS efficiency in different tomato organs (leaves, flowers and fruits). Zhou et al. (2012) applied Potato Virus $\mathrm{X}$ in VIGC technology (virus-induced gene complementation) and determined functions of some TFs involved in regulation of fruit ripening genes in tomato fruits ( $\mathrm{rin}$ mutant).

\section{Genetic engineering approaches and achievements}

The growing environmental stresses of the modern world constitute a serious problem for global productivity of crop plants. Obviously, abiotic stress factors unfavourably impact the whole physiology of plants by changing their metabolism, growth and development (Mishra et al. 2012). Therefore, the genetic engineering of crop plants aiming at enhancement of tolerance to different environmental stresses has recently gained great significance. In contrast to the traditional selective breeding, genetic modification (GM technology) allows for faster and more effective obtaining of plants (including tomato) tolerant to abiotic stresses, resulting in increased food supply. To date, there have been many attempts to increase plant tolerance to a wide range of stress factors (e.g. salinity, drought, heavy metals, oxidative stress). These approaches included introduction of various genes involved in regulatory and signalling pathways, as well as stress-mitigating enzymes (Vincour and Altman 2005). Modifications of genes encoding functional and structural proteins were also made (Table 2). Here, some examples of genetic modifications of target sequences encoding molecules involved in stress adaptation are presented. 


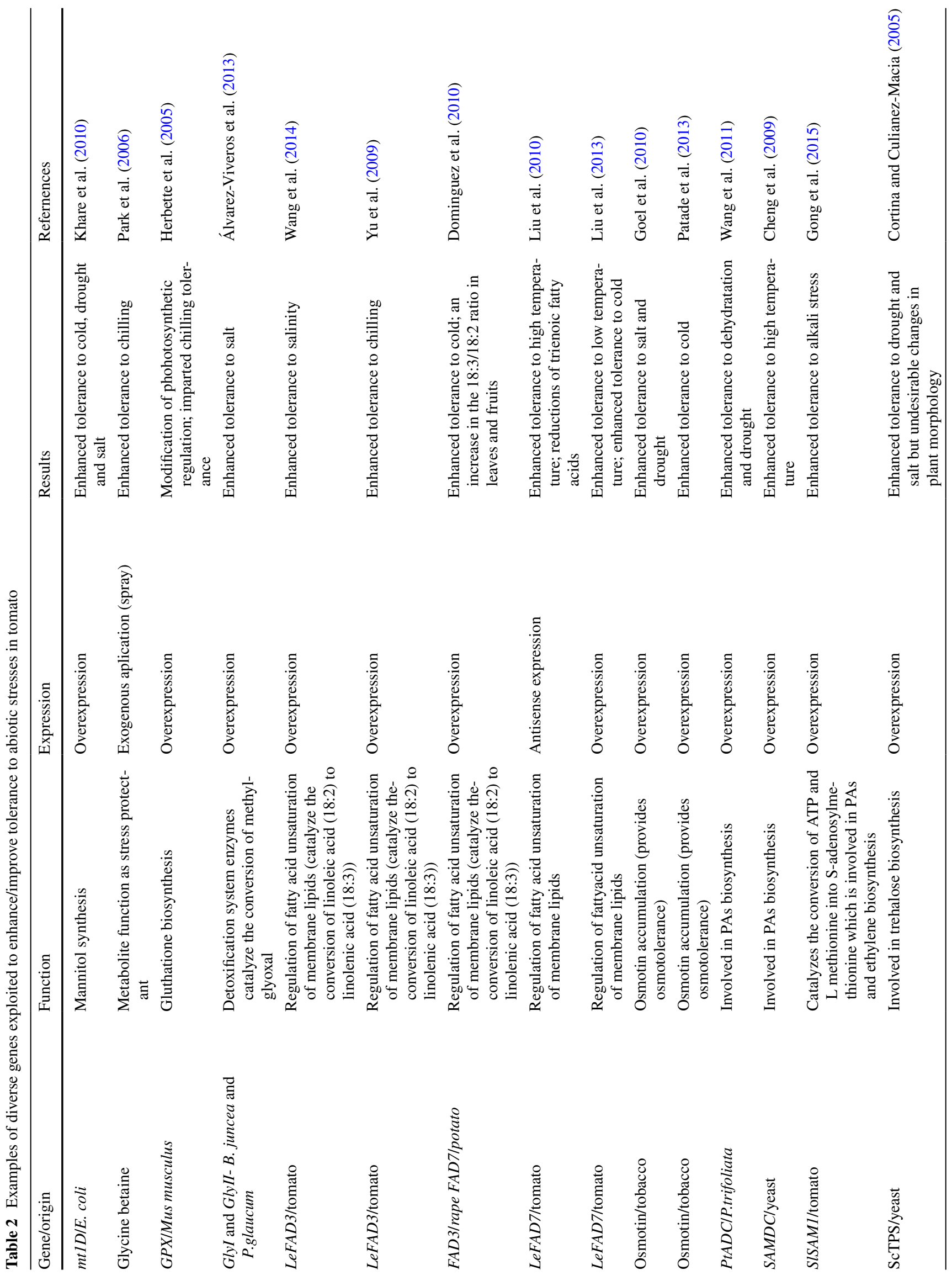




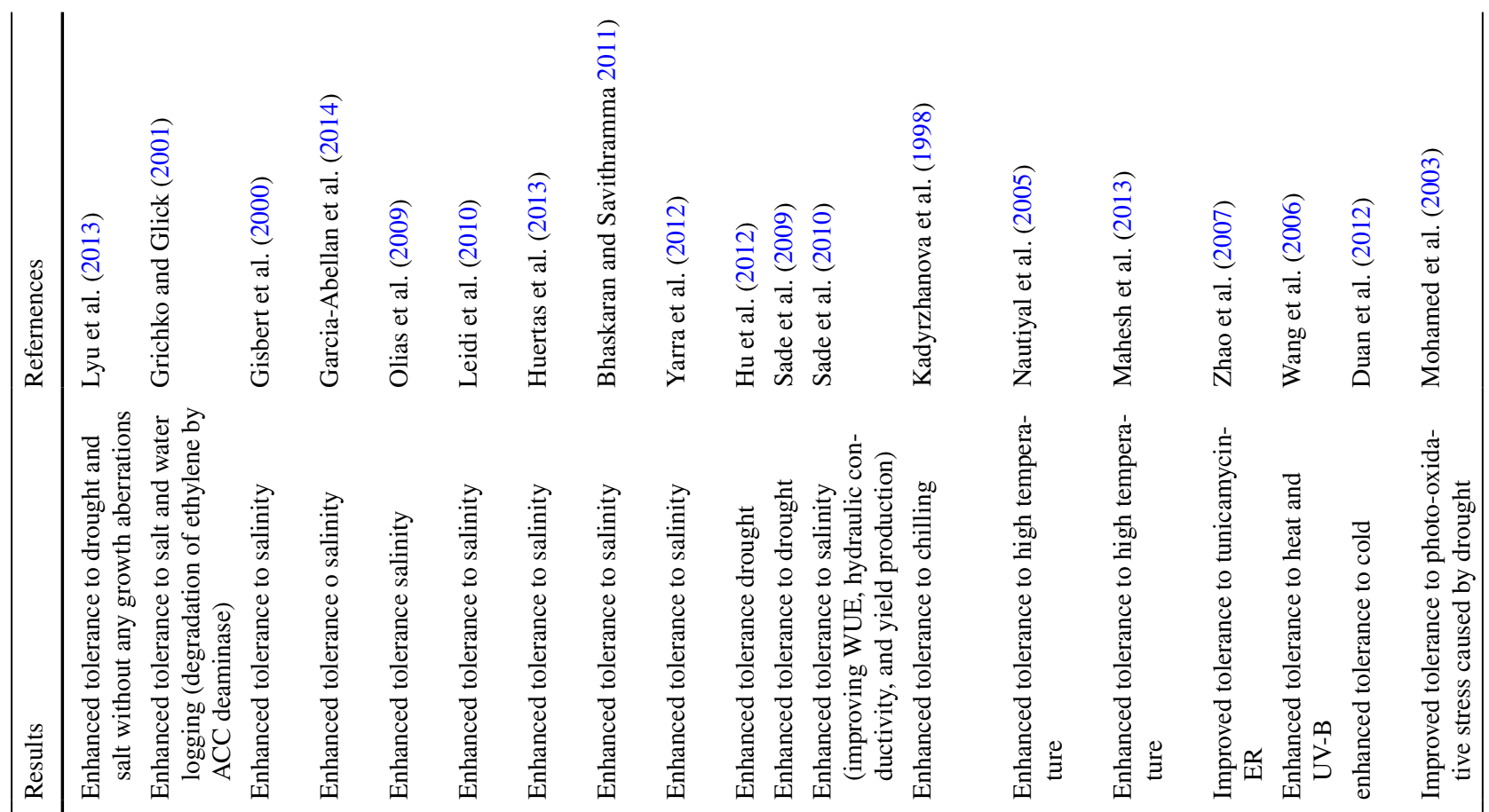

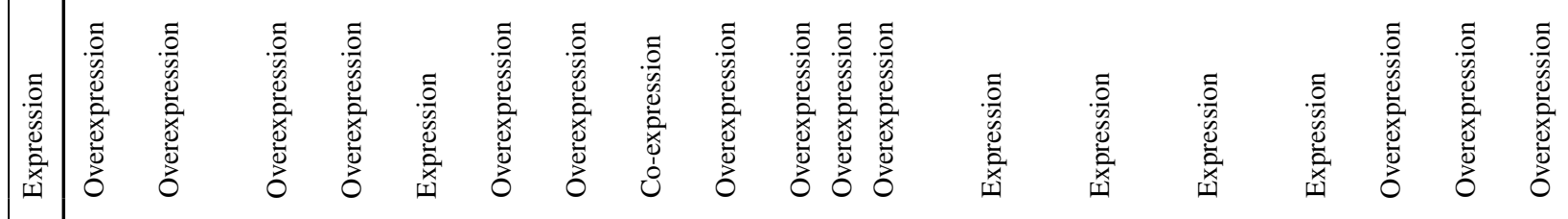

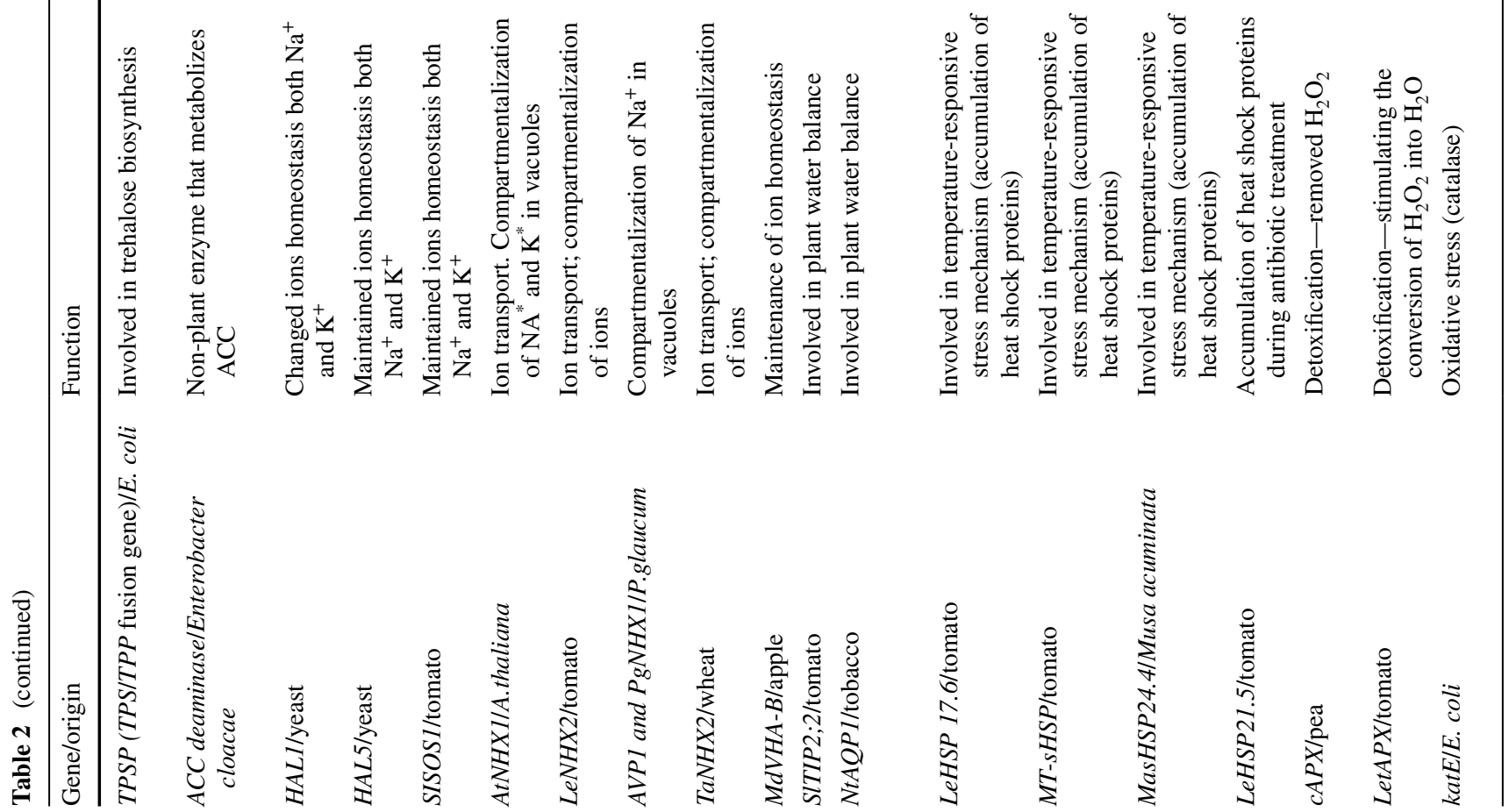




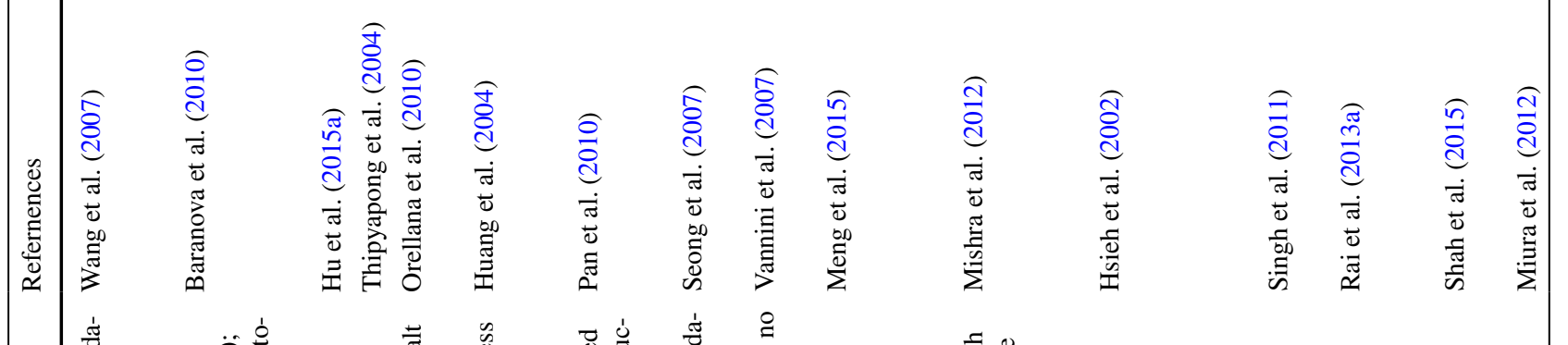

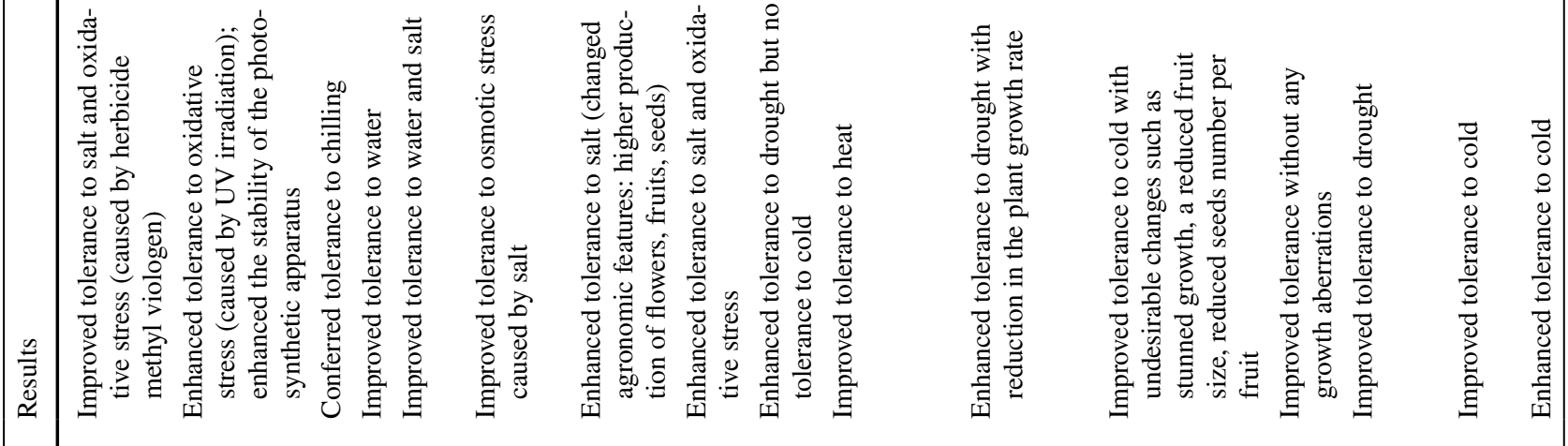

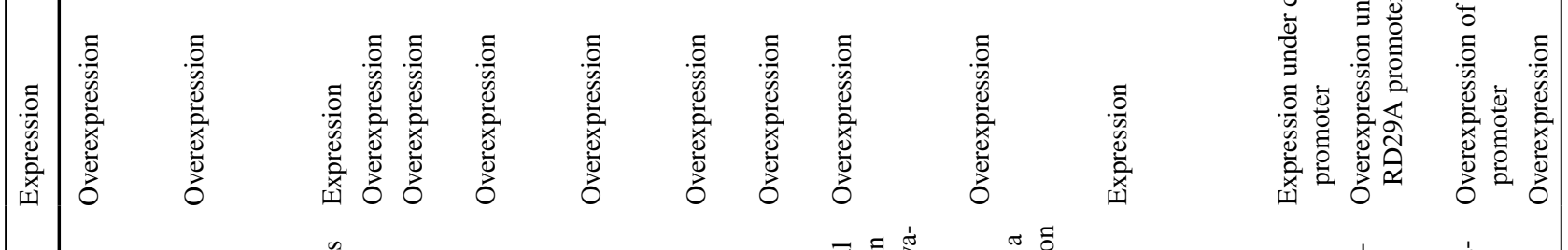

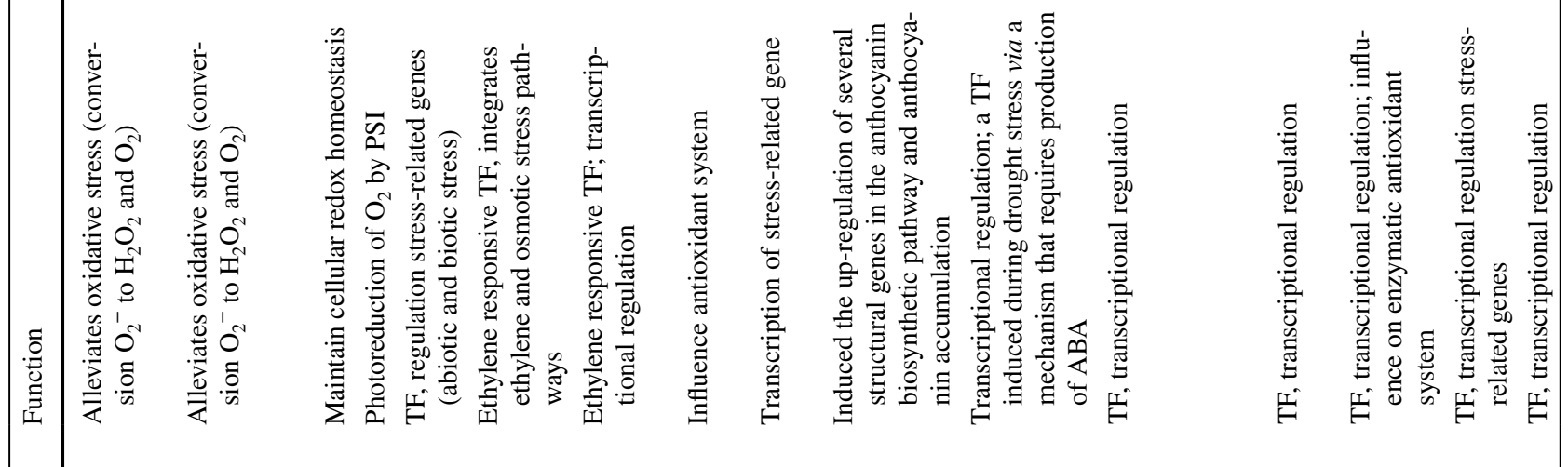
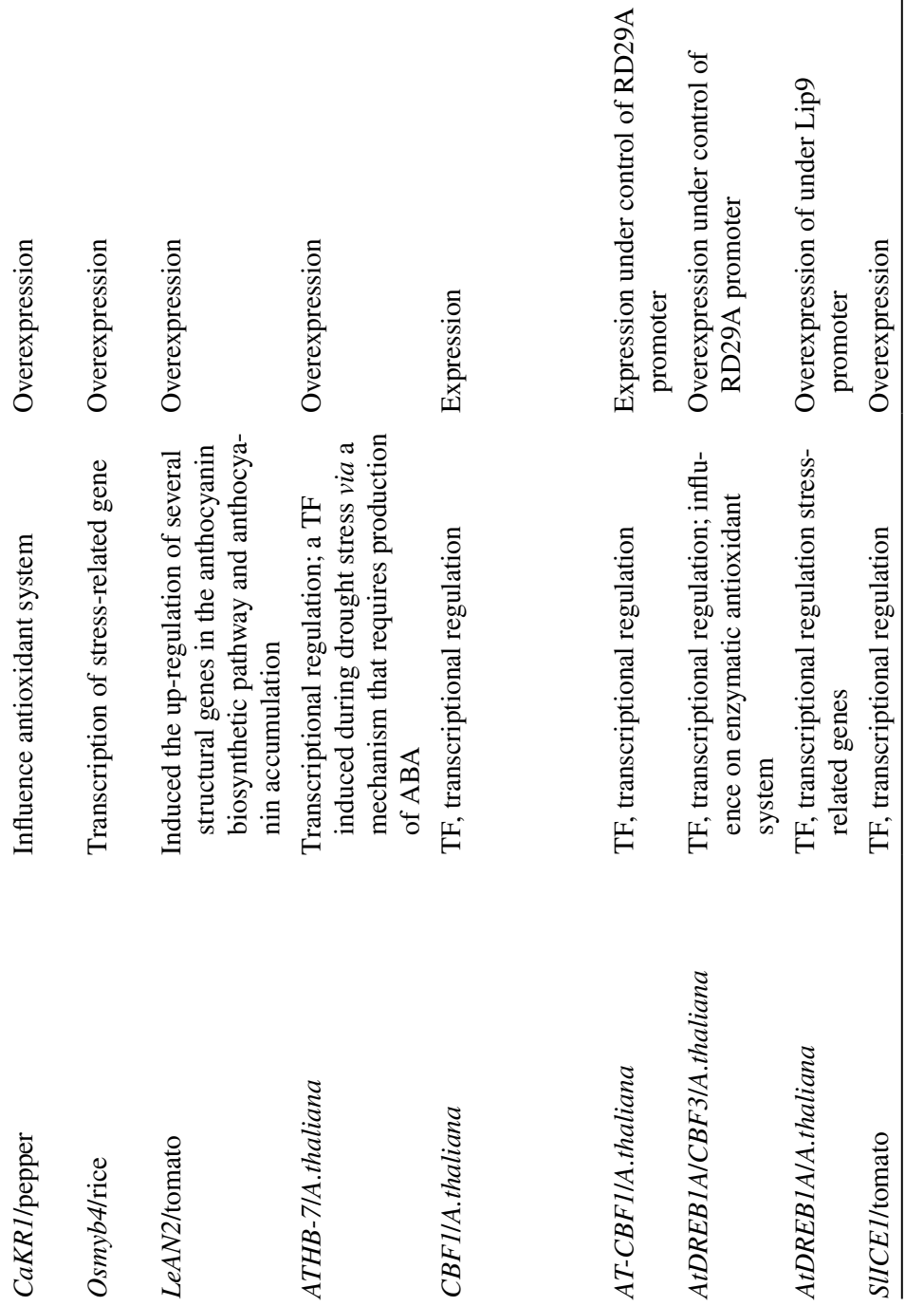


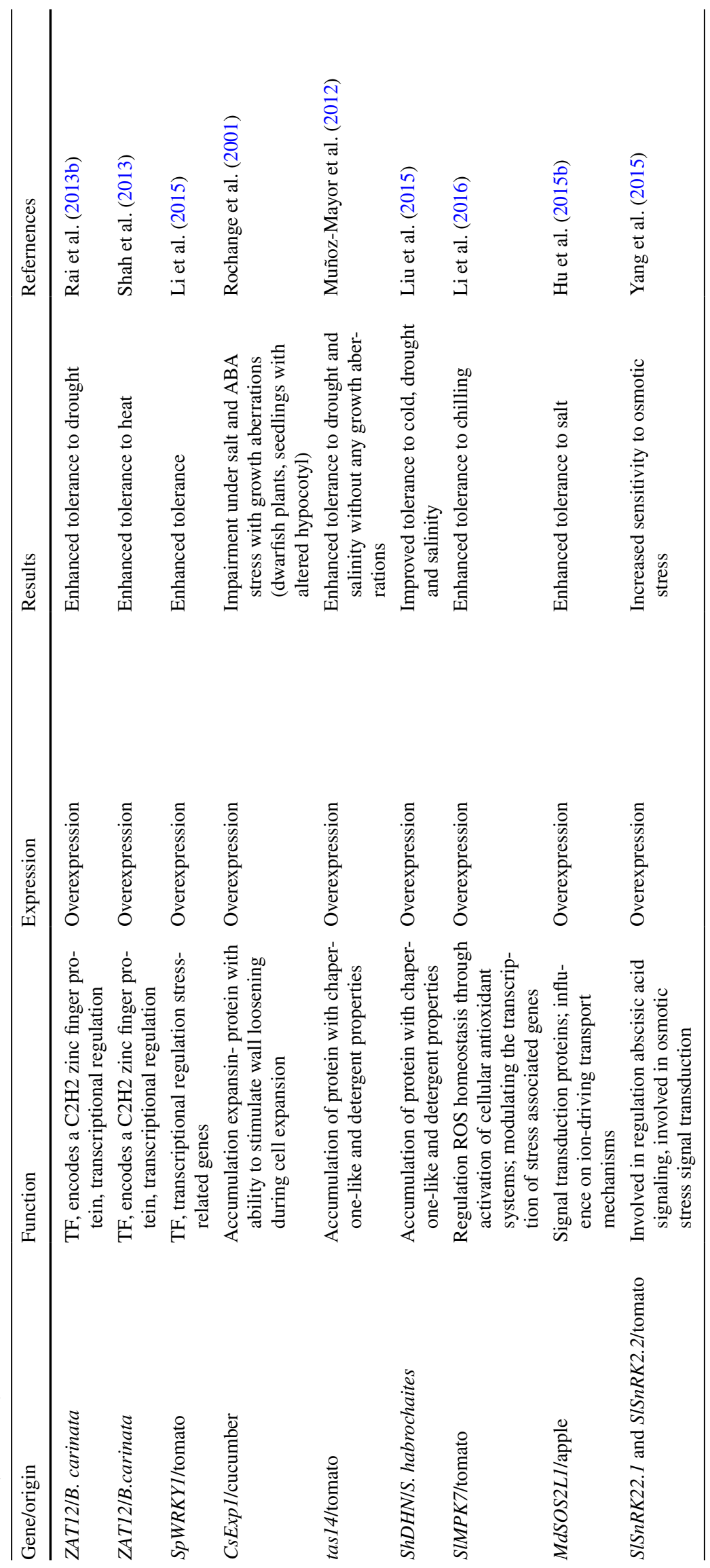




\section{Mannitol}

Mannitol, because of its properties, is widely used in the pharmaceutical industry and in food processing. Mannitol is a six-carbon, non-cyclic sugar-alcohol playing a role in the coenzyme adjustment, free-radical scavenging, storage of energy and osmoregulation. This compound is synthesised from fructose in plants through the action of mannitol-1-phosphate dehydrogenase (mt1D). It has been reported that overexpression of the $m t 1 D$ gene from Escherichia coli under control of the CaMV $35 \mathrm{~S}$ promoter in genetically engineered lines of tomato plants (cv. Pusa Uphar) enhanced tolerance to abiotic stresses including cold, drought and salinity (Khare et al. 2010). Genetically modified plants compared to wild-type ones were characterized by reduced leakage of electrolytes with a simultaneous increase in lipid peroxidation. Moreover, it was noticed that the levels of activity of antioxidant enzymes (superoxide dismutase and catalase) were also substantially boosted.

\section{Glycine betaine}

Glycine betaine (GB, $N$-methyl-substituted derivative of glycine) is an organic osmolyte that accumulates in numerous plant species in response to environmental stressors, including UV radiation, extreme temperatures, salinity, drought and heavy metals. This compound also occurs naturally in a variety of animals and microorganisms (Giri 2011). In plants, GB abundantly occurs in chloroplasts, where it has a crucial role in regulation and the preservation of the thylakoid membrane, hence supporting photosynthetic efficacy. Glycine betaine is synthesised by a two-stage process of choline oxidation followed by its conversion to betaine aldehyde (BADH) by choline monooxygenase (Park et al. 2007). Presumably, in response to abiotic stressors, GB acts not only as a molecular chaperone but also is responsible for protection of transcription and translation machinery and it also stabilises a complex of proteins and membranes (Chen and Murata 2011). Furthermore, this compound may indirectly induce $\mathrm{H}_{2} \mathrm{O}_{2}$-mediated antioxidant mechanisms, e.g. it may enhance catalase gene expression and therefore catalase activity (Park et al. 2006). Several studies revealed that two approaches the genetically modified biosynthetic pathway of glycine betaine and the exogenous usage of GB, significantly enhanced the response of plants to abiotic stress (Park et al. 2006).

\section{Glutathione}

Glutathione (GSH) appears to be one of the crucial antioxidants, having diverse roles in plants. GSH is synthesised from 1-glutamine, 1-cysteine, and 1-glycine in two ATP requiring steps catalysed by the enzymes $\gamma$-glutamylcysteine ligase and glutathione synthetase (Noctor et al. 2012). This low molecular weight thiol acts as a protector of cells and tissues against a broad range of peroxidases, xenobiotics and heavy metals. It also takes part in reducing hydrogen peroxide content (Hossain et al. 2012; Noctor et al. 2012). The redox state of glutathione as well as its contents in plants vary during the action of stressors. GSH is involved in plant tolerance to abiotic and biotic stresses (Noctor et al. 2012).

Interesting studies by Herbette et al. (2011) showed that overexpression of glutathione peroxidase (GPx, enzyme that uses glutathione as a substrate) made tomato plants more tolerant to abiotic stress (mechanical one) and less resistant to biotic stress (parasites).

The glyoxalases are enzymes responsible for detoxification of methylglyoxal as well as other reactive aldehydes that appear during metabolism. The detoxification process consists of two steps action of two enzymes i.e. glyoxalase I and glyoxalase II using glutathione as a catalytic cofactor (Mustafiz et al. 2010). Some researchers implied that overexpression of two genes, GlyI (glyoxalase I) and GlyII (glyoxalase II), might remarkably enhance tolerance of tomato to salinity, suggesting indirectly the significance of glutathione. Both reduction of lipid peroxidation and production of $\mathrm{H}_{2} \mathrm{O}_{2}$ were observed in transgenic tomato lines treated with high concentration of $\mathrm{NaCl}(800 \mathrm{mM})$. Furthermore, control plants were characterized by a significant decrease in the chlorophyll $\mathrm{a}+\mathrm{b}$ content in comparison to the transgenic lines (Álvarez-Viveros et al. 2013).

\section{Fatty acid desaturases}

Fatty acid desaturases (FADs) are involved in plant responses to multifarious abiotic stresses including drought, salt and heat. Nevertheless, their function in plant resistance to e.g. drought and salt stress remains unknown (Zhang et al. 2012). Wang et al. (2014) provided clear evidence of connection between unsaturated fatty acids and tolerance to salt stress. They obtained transgenic tomato by overexpressing sense and antisense sequences LeFAD3-encoding omega-3 fatty acid desaturase that plays an important role in the regulation of the membrane lipid unsaturation. Since it converts 18:2 linoleic acid to $18: 3$ linolenic acid which presence keeps the membrane intact and protects the photosystem, it improves the rate of photosynthesis providing energy and substrates for growth. Therefore, plants bearing the sense sequence and displaying higher expression of desaturase, grew and developed more vigorously in comparison with the plants bearing the antisense sequence showing lower expression. Salt stress had also a negative impact on growth of control plants (WT). The results also showed that the accompanying increase in SOD and APX may have mitigated the 
photoinhibition caused by the raised level of ROS in plants carrying the sense sequence. The obtained data implied that unsaturated fatty acids have an essential role in a plant reaction to salinity which corresponds with previous data that FAD3 overexpression may contribute to an increase in $\alpha$-linolenic acid (ALA, 18:3) levels in plants (Yu et al. 2009). Yu et al. (2009) demonstrated that overexpression of tomato omega-3 fatty acid desaturase (LeFAD3) gene caused increased tolerance of tomato plants to cold stress, which was attributed to the increased level of the 18:3 fatty acid that alleviated membrane damage. Likewise, overexpression of the $F A D 3$ gene in genetically engineered tomato plants resulted in increased fruit flavour and also improved the tolerance of plants to chilling stress (Dominguez et al. 2010). On the other hand, antisense-mediated reduction of LeFAD7 improved the high-temperature (HT) tolerance of tomato plants through an increased level of fatty acids saturation and also mitigated photoinhibition of the photosystem (PS) II (Liu et al. 2010). These results suggest that the increase in HT tolerance in tomato plants with antisense expression of LeFAD7 may be increased by fatty acid fluxes, which cause a series of physiological changes. In contrast to these findings, other results indicated that overexpression of LeFAD7 enhanced low-temperature (LT) tolerance. This can be attributed to changes in the composition of membrane lipids in tomato plants (a higher content of trienoic fatty acids in comparison to the content of dienoic fatty acids) (Liu et al. 2013).

\section{Osmotine}

Osmotine is a stress-responsive 24-kDa protein which abundantly appears in plants during both abiotic and biotic stresses. This protein plays a pivotal role in osmotic regulation of cells by inducing synthesis and accumulation of certain solutes into cell compartments. Goel et al. (2010) reported that genetically modified tomato plants with overexpression of the osmotin gene had higher proline and chlorophyll content, relative water content (RWC) and leaf expansion than control plants under drought stress conditions. It was also clearly demonstrated that the increased content of both proline and osmotin during chilling stress in transgenic tomato plants made them more tolerant to cold (Patade et al. 2013).

\section{Polyamines}

Polyamines (PAs) are a class of organic molecules and include spermine $(\mathrm{Spm})$, putrescine (Put), tetramine and cadaverine $(\mathrm{Cad})$. In plants, polyamines are not only involved in response to environmental stresses, but play a crucial role in many other physiological processes as well e.g. embryogenesis, organogenesis, floral initiation and development, fruit development and ripening, leaf senescence (Minocha et al. 2014). Recently it has been reported that PAs are interrelated with miscellaneous metabolic pathways and involved in hormonal 'cross-talks' that are important to the plant stress responses (Alćazar et al. 2010). Moreover, research on transgenic overexpression of loss-function mutants provided clear evidence of the preventive role of polyamines in plant response to abiotic stress. Putrescine is formed by decarboxylation of ornithine, the reaction carried out by ornithine decarboxylase, ODC, or decarboxylation of arginine in indirect pathway, the reaction carried out by arginine decarboxylase, ADC. It was reported that transgenic tomato lines with overexpression of PtADC (a gene from Poncirus trifoliate) displayed enhanced tolerance for dehydratation and drought stress (Wang et al. 2011). Under the aforementioned stress conditions, a remarkable decrease in ROS (their presence accompanies the drought stress) in comparison to WT plants, was noticed. A lot of research has pointed out that introduction of a broad range of genes involved in polyamine biosynthesis, originating from various sources-both plants and animals-has resulted in improved tolerance to diverse stresses in such plants as tobacco, tomato or rice (including osmotic, salt stresses, heat, freezing, drought) (Alćazar et al. 2010). Cheng et al. (2009) confirmed that tomato plants with overexpression of SAMDC gene (SAM decarobxylase, catalyses the synthesis of S-adenosylmethionine, a substrate in polyamine formation) from Saccharomyces cerevisiae showed better tolerance to HT in comparison to WT plants. Transgenic lines were characterized by a high level of polyamine accumulation (1.7-2.4 times more than under normal conditions). Gong et al. (2015) showed that overexpression of S-adenosylmethionine synthetase (SISAM1, another enzyme in polyamine synthesis) in tomato callus conferred tolerance to alkali stress. It was accompanied by an increased content of $\mathrm{H}_{2} \mathrm{O}_{2}$ and PA.

\section{Trehalose}

Trehalose, a disaccharide molecule ubiquitous in diverse groups of organisms (invertebrates, yeast, bacteria) exposed to stress conditions, is an effective 'osmoprotectant' (Cortina and Culianez-Macia 2005). Trehalose protects membranes and proteins and makes cells dehydration tolerant. It has some unique physiochemical features such as stability at low $\mathrm{pH}$ and height temperatures which make it a perfect stress protectant. Moreover, unlike other sugars (e.g. sucrose), trehalose is not involved in chemical reaction with protein (Maillard reaction) (Lyu et al. 2013). Some tolerance characteristics were obtained with genetic engineering by modifying trehalose metabolism. Tomato plants overexpressing the ScTPS1 gene (encoding enzyme in trehalose synthesis) were more tolerant to drought, salt, 
and oxidative stresses than the control plants. However, they had some pleiotropic changes, including stiff darkgreen leaves, erected branches, thick shoots, abnormal root system development. Further, leaves of transgenic tomato exhibited chlorophyll and starch contents higher than in the control plants (Cortina and Culianez-Macia 2005). Undesirable changes in plant morphology can result from differences in the accumulation of trehalose-6-phosphate in cells, the intermediate metabolite that is responsible for these changes.

\section{Ethylene biosynthesis - an example of modification of the expression of genes regulating phytohormone levels}

Phytohormones play crucial roles in plants adaptation to environmental stresses by mediating diverse acclimatization responses. The most important are abscisic acid (ABA), ethylene (ET), jasmonic acid (JA), cytokinin (CK), salicylic acid (SA). ABA, SA, or ET, all of which are known to accumulate to higher levels under stress conditions and under the influence of different genes involved in defence mechanisms against stresses. Therefore, it is fully justified to characterise the molecular mechanism of e.g. ET biosynthesis, signalling or action because it would greatly facilitate the modification of phytohormone biosynthetic pathways for obtaining genetically modified plants with improved resistance to environmental stresses. ACC deaminase is one of the important enzymes involved in the biosynthesis of ethylene, displaying the ability of cleaving the ethylene precursor (ACC) (Glick et al. 2007; Gururani et al. 2015). Grichko and Glick (2001) generated transgenic tomato lines overexpressing ACC deaminase derived from bacteria. These plants revealed a decreased level of ethylene, enhanced tolerance to salt and water logging de to the suppression of ethylene synthesis by ACC deaminase.

\section{Aquaporins as an example of modification of the expression of genes encoding proteins involved in water transport}

Aquaporins (AQP), membrane channels, are responsible for adjustment of water transport in whole plant. Thus, these integral membrane proteins function as both $\mathrm{CO}_{2}$ and water channels in plants. Based on numerous studies, AQPs were implied to have a pivotal role in water use efficiency (WUE) and plant water balance ( $\mathrm{Li}$ et al. 2014). One of the used strategies is overexpression of the aquaporin genes. Spectacular results were obtained with SITIP2:2, a stressinduced aquaporin of tomato (Sade et al. 2009). Overexpression of the tonoplast $A Q P$ SITIP2;2 substantially altered water relations, also enhancing transpiration and modifying leaf water potential maintenance under drought. Expression of this transgene also positively influenced plant growth and fruit yield under both control and water stress conditions. Furthermore, Sade et al. (2010) revealed that overexpression of $N t A Q P 1$ gene (originating from Nicotiana tabacum) in transgenic tomato lines provoked higher levels of net photosynthesis, as well as stomatal conductance and whole plant transpiration under salinity conditions in contrast to WT plants.

\section{Modification of the expression of genes encoding ion transport proteins}

Several paths have been proposed to enhance tolerance to salt stress in susceptible plants. One of the biotechnological approaches to enhance drought and salt tolerance in plants is modifying the expression of genes engaged in ion transport. Pineda et al. (2012) proposed the transformation of plants with $H A L$ genes (originating from Saccharomyces cerevisiae) to influence cation transport systems $\left(\mathrm{K}^{+}\right.$and $\mathrm{Na}^{+}$). Gisbert et al. (2000) showed that tomato plants carrying the $H A L 1$ gene were characterised by enhanced tolerance to salinity. Taking into consideration intracellular cation ratios $\left(\mathrm{K}^{+}\right.$to $\left.\mathrm{Na}^{+}\right)$, it was found that transgenic tomato lines were characterised by higher ability to retain $\mathrm{K}^{+}$in comparison to control plants under salt stress. Therefore, overexpression of the yeast gene HAL5 in tomato improves tolerance to salt stress by reducing shoot $\mathrm{Na}^{+}$retention for a long time. This was the result of reduced transport of $\mathrm{Na}^{+}$ from roots to shoots during the salt stress, regardless of its severity. Moreover, maintaining $\mathrm{Na}^{+} / \mathrm{K}^{+}$homeostasis over time was correlated with alteration in the transcript levels of cation $\left(\mathrm{Na}^{+}\right.$and $\left.\mathrm{K}^{+}\right)$transporters (e.g. SlHKT1;2 and SlHAK5) (Garcia-Abellan et al. 2014). Olias et al. (2009) revealed that the SISOS 1 antiporter is vital for the maintenance of ion homeostasis under salt stress and crucial for distribution of $\mathrm{Na}^{+}$in the whole plant. Due to the involvement of protein transporters in the transport of ions across the tonoplast into vacuoles, the strategy based on overexpression of antiporter gene seems to have great potential. Leidi et al. (2010) reported that overexpression of AtNHXI in tomato plants resulted in increased resistance to salinity. The authors implied that $A t N H X I$ was responsible for the facilitation of active $\mathrm{K}^{+}$uptake at the tonoplast and the intracellular distribution of $\mathrm{K}^{+}$. Similarly to these findings, Huertas et al. (2013) observed that LeNHX2 (class II $\mathrm{NHX}$ transporter), enhanced resistance to $\mathrm{NaCl}$ by changing cytosolic $\mathrm{K}^{+}$content or adjusting the activities of $\mathrm{K}^{+}$ transport systems. Alternatively, improvement in salt tolerance in genetically engineered tomato by co-expression of Arabidopsis $\mathrm{H}^{+}$-pyrophosphatase and Pennisetum glaucum vacuolar $\mathrm{Na}^{+} / \mathrm{H}^{+}$antiporter was reported (Bhaskaran and 
Savithramma 2011). Similarly, it was shown that overexpression of TaNHX2 (a wheat $\mathrm{Na}^{+} / \mathrm{H}^{+}$antiporter gene) enhanced tolerance to salt stress $(100$ or $150 \mathrm{mM} \mathrm{NaCl})$ in genetically modified tomato plants (Yarra et al. 2012). Additionally, these results revealed that transgenic tomato lines had a substantial relative water and chlorophyll content under salt stress conditions compared to WT plants. Some studies indicated an essential role of vacuolar $\mathrm{H}^{+}$-ATPase (V-ATPase) under drought stress ( $\mathrm{Hu}$ et al. 2012; Dong et al. 2013; Zhang et al. 2014). This particular multisubunit enzyme is responsible for the maintenance of cellular stability under stress conditions by stimulating secondary transport. It was demonstrated that overexpression of MdVHA-B (subunit of the V-ATPase from apple) in transgenic tomato plants conferred better tolerance to drought stress, which was accompanied by RW loss and decreased malondialdehyde (MDA) content, with simultaneous increase in $\mathrm{H}^{+}$ATPase activity and free proline levels in comparison to WT plants (Hu et al. 2012).

\section{Heat shock proteins}

Plants are able to synthesise a variety of sHSPs (small Heat Shock Proteins) encoded by multigene families. sHSPs proteins are present in different cellular compartments, including cytosol, chloroplast, mitochondria and also endoplasmic reticulum (ER). Proteins act as chaperones and they are directly involved in intracellular protein distribution as well as their appropriate folding or degradation. Besides, this sHSPs also play a protective role against multifarious environmental stresses such as salinity, heat, cold, drought, heavy metal and oxidative stress (Al-Whaibi 2011). The large variety of plant sHSPs presumably reflects molecular adaptation to stress. The transcription of HSP encoding genes is ordered by regulatory proteins-heat stress transcription factors (HSFs). They occur in an inactive form mainly in the cytoplasm. Mishra et al. (2002) studied individual HSFs. They obtained genetically modified tomato with changed expression of HsfA1, HsfA2, or HsfB1. Analyses revealed that HsfA1 played an exceptional role as a primary controller in the synthesis of Hsfs A2 and B1 as well as Hsps. Furthermore, post-transcriptional silencing of the HsfAl gene also causes severe defects in thermotolerance and plant development at elevated temperatures. Kadyrzhanova et al. (1998) showed that transcription of the LeHSP 17.6 gene was heat induced and maintained at an enhanced level during subsequent exposure to chilling temperature and thus correlated with tolerance to chilling injury. These findings are consistent with the results of Sabehat et al. (1996). They reported that protection of tomato from chilling injury afforded by pre-storage heat treatment was correlated with the induction of transcription of HSPl7 and HSP 70 mRNAs and with translation of the HSP 17 and HSP 23 proteins, which persisted during subsequent storage of the fruit at chilling temperature. Certain types of small heat shock proteins are known to appear under normal growth conditions and also during plant development. Notwithstanding this fact, Nautiyal et al. (2005) could not observe the MT-sHSP in WT plants at optimum or high temperatures but in transgenic tomato plants (harbouring MT-sHSP gene) thermotolerance was observed during high temperature stress. A similar positive correlation was recorded by Mahesh et al. (2013). The gene MasHSP24.4 from wild banana was expressed in different tomato plant tissues including root, shoot and stem under $45^{\circ} \mathrm{C}$ treatment. The genetically modified tomato lines displayed better growth productivity at the regeneration stage. Some data indicated that particular ER-located sHSPs in plants may have play the molecular chaperone functions stabilising proteins under stress conditions. Genetically engineered tomato carrying LeHSP21.5 displayed improved tolerance to tunicamycin-ER stress inducer (Zhao et al. 2007).

\section{Modification of the expression of genes encoding enzymes in the antioxidant system}

\section{Glutharedoxins}

Maintenance of intracellular redox homeostasis depends upon oxidoreductases-glutharedoxins (GRXs). Recently, it has been reported that tomato plants with $A t G R X$ gene (originating from A. thaliana) expression were better adapted to chilling stress in comparison to WT plants. In transgenic lines no undesirable changes in morphology of plants (growth and development) were observed. (Hu et al. 2015a).

\section{Catalase}

Catalase (CAT), an antioxidant enzyme, belongs to ROS scavengers which are responsible for decomposing $\mathrm{H}_{2} \mathrm{O}_{2}$ to water and oxygen. The catalase (catE) gene originating from Escherichia coli has higher affinity to hydrogen peroxide compared with plant catalase, and it was introduced into the chloroplasts of tomato leaf (Mohamed et al. 2003). The results clearly demonstrated that transgenic tomato with overexpression of the $c a t E$ gene were more tolerant to oxidative stress caused by the herbicide paraquat. Furthermore, genetically engineered plants displayed increased tolerance to oxidative damage resulting from cold or drought stress. 


\section{Ascorbate peroxidase}

Ascorbate peroxidase (APX) converts $\mathrm{H}_{2} \mathrm{O}_{2}$ into $\mathrm{H}_{2} \mathrm{O}$, with ascorbate as an electron donor. So far several diverse APX isoforms have been found in individual sub-cellular compartments (e.g. peroxisome, mitochondria, chloroplasts) and cytosol. The expression of APX genes can be switched on by environmental stressors. Thus, they are directly engaged in protecting plants against unfavourable environmental conditions. Wang et al. (2006) found that genetically engineered tomato plants with overexpression of the $C A P X$ gene had improved tolerance to heat stress and UV-B, while overexpression of LetAPX (tomato thylakoidal ascorbate peroxidase gene) in tomatoes increased the tolerance to cold stress, which was accompanied by a significant reduction in chlorophyll as well as GSH contents, and APX activities in comparison to the control plants (Duan et al. 2012). Moreover, the transgenic tomato lines were characterised by decreased MDA content, levels of hydrogen peroxide $\left(\mathrm{H}_{2} \mathrm{O}_{2}\right)$ and ion leakage, higher maximal photochemical efficiency of PSII (Fv/Fm) and higher net photosynthetic rate (Pn) (Duan et al. 2012). These findings suggest that overexpression of LetAPX has a pivotal role both in mitigating photoinhibition and improving plant resistance to cold stress.

\section{Superoxide dismutases}

In higher plants superoxide dismutase (SOD) acts as an antioxidant enzyme and a scavenger of ROS which is responsible for catalysing production of $\mathrm{O}_{2}$ and $\mathrm{H}_{2} \mathrm{O}_{2}$ from superoxide radicals. Plant cells contain several isoforms of SOD differing in the metal $\left(\mathrm{Fe}^{2+}, \mathrm{Mn}^{2+}\right.$, and $\left.\mathrm{Cu}^{2+}\right)$ in the active site of the enzyme, as well as their localisation in sub-cellular compartments including cytosol, mitochondria, peroxisomes and chloroplasts (Wang et al. 2007; Aydin et al. 2014). The impact of elevated expression of Mn superoxide dismutase (Mn-SOD) on salt stress tolerance was investigated using transformed tomato plants (Wang et al. 2007). This research indicated significantly improved tolerance to both salt stress and to herbicide, methyl viologen (MV). Additionally, transgenic plants displayed decreased electrolyte leakage in comparison to control plants, implying that overexpression of Mn-SOD in the genetically modified plants reduced cellular damage caused by reactive oxygen species.

In transgenic tomato lines, the FeSOD gene from A. thaliana enhanced the stability of the photosynthetic apparatus of plants during oxidative stress caused by UV irradiation. Moreover, expression of the FeSOD gene had a significant influence on changes of cell ultra-structure sub-compartments of tomato leaves (Baranova et al. 2010). Baranova et al. (2014) examined the impact of expression of the $A$. thaliana FeSODI gene on the dark respiration rate of transgenic tomato regenerants without salinity as well as under chloride and sulphate salinity. It was observed that transgenic tomato reacted differently to $\mathrm{NaCl}$ and $\mathrm{NaSO}_{4}$ treatments. Moreover, it was shown that expression of FeSODI essentially affected the dark respiration rate (DRR).

\section{Modifications of the expression of regulatory genes engaged in abiotic stress tolerance}

To obtain the improved tolerance to a broad range of environmental stresses, modifications of the expression of a single gene engaged in tolerance response have been developed. However, such an approach may have a limited effectiveness. Therefore, both modifications of transcription factors alone or their interference with different single gene manipulations (another than TF), appear a more favourable solution. Since transcription factors trigger cascades of gene expression that respond to various stress stimuli enhancing tolerance towards different stresses, a single modification of a TF gene results in simultaneous multiple responses (multiple function/pathway affecting). That makes TFs an attractive target category for regulon biotechnology to work on improving adaptation.

\section{Transcription factors (TFs)}

Transcription factors (sequence-specific DNA-binding factors) are a large group of proteins involved in gene expression and they are classified into particular families (Shinozaki and Yamaguchi-Shinozaki 2007). Some of TFs were known to act during plant adaptation to stresses e.g. during drought response: CCAAT-binding (e.g. C3H2 zinc finger protein ZFP), NAM (no apical meristem), ATAF1-2, CUC2 (cup shaped cotyledon), NAC (e.g. stress-responsive NAC-SNAC), bZIP (e.g. ABA responsive element binding protein/ABRE binding factor-AREB/ABF), $\mathrm{AP}$ / / EREB (e.g. DRE binding protein/CRT binding factorDREB/CBF) (Yang et al. 2010). Since numerous studies have indicated the transcription factors and cis-acting elements involved in gene regulation strictly connected with response to stress, genetic manipulation at this level would seem highly desirable.

An example can be found among a class of bZIP TFs, ABF/AREB (activated by ABA) (Sarkar and Lahiri 2013). AREBs were recognized to be engaged in response to abiotic stress in Solanum genus (Yanez et al. 2009). It was reported that the expression of TF encoding gene, SIAREB, in tomato and tobacco leaves upregulated the expression of stress-responsive genes, including the LEA genes, RD29B gene and trehalose-6-phosphate phosphatising gene. In further studies, it was proved that genetically modified tomato 
plants with overexpression of SIAREB1 showed improved tolerance to water and salt stress (Yanez et al. 2009; Hsieh et al. 2010; Orellana et al. 2010). Similarly, the cytokinin response factors (CRFs), a subgroup of AP2/ERF transcription factors, were shown to take part in tomato response to diverse abiotic stresses, including oxidative, flooding, osmotic, temperature and drought ones. Since SlCRF3 and SlCRF5 genes varied in regulation controlled by cytokinins under unfavourable conditions, their role as regulators during stress is implied (Gupta and Rashotte 2014). Other studies demonstrated that also the group of EFR (Ethylene Response Factor) TFs was involved in plant stress response (Lorenzo et al. 2003). Biochemical analyses showed that TERF1 overproduction in tobacco plants affected the initiation of the expression of ethylene-inducible genes (containing GCC box, a well conserved region of their promoters) and improved their tolerance to osmotic stress. Further research demonstrated that TRF1 transgenic tomato lines were salt tolerant as well. These data implies that TERF1 acts as a linker between the ethylene and osmotic responses coupling two pathways of responses (Huang et al. 2004). Similarly, the analysis of Sl-ERF.B.3 (the ethylene response factor B.3 originating from tomato) revealed its engagement in response to a wide range of stresses, including flooding, heat, cold, drought as well as salinity (Klay et al. 2014). Its expression is up- or downregulated by the aforementioned stresses.

Moreover, transcription factors can act as linkers of signals from diverse pathways combining responses to abiotic and biotic stressors. Seong et al. (2007) studying the transgenic tomato with overexpression of the CaKRI gene (encoding an ankyrin repeat domain zinc finger) revealed increased resistance to biotic stress (Phytophthora infestans) and tolerance to abiotic stress (oxidative and salt stress). The transgenic tomato with overexpression of the rice Osmyb4 gene coding for the MYB transcription factor, displayed enhanced tolerance to drought conditions as well as resistance to the Tomato Mosaic Virus (ToMV) (Vannini et al. 2007).

Interesting findings were reported by Meng et al. (2015) regarding the overproduction of LeAN2 transcription factor in tomato plants. These results clearly show improved tolerance to heat stress and an increased level of anthocyanins. Moreover, LeAN2 had an important function in maintaining low ROS levels and alleviating photoinhibition of PSII and membrane damage when plants were subjected to high temperature stress.

The presented results show how transcription factors can work as master molecular switches controlling clusters of genes induced in response to a variety of stressors (found also among genes encoding key tolerance proteins described in other sections). Therefore, considering them as target candidates for genetic engineering aiming at counteracting the effects of abiotic stress seems completely justified. Examples of interesting modifications of tomato plants can be found in a number of papers, e.g. by Hsieh et al. (2002), Singh et al. (2011), Mishra et al. (2012), Miura et al. (2012), Patade et al. (2013), Rai et al. (2013a, b), Shah et al. (2013), Li et al. (2015), Shah et al. (2015) and Zhao et al. (2015).

\section{Modifications of expression of genes encoding various proteins}

\section{Systemins}

Systemin is considered as a signal peptide engaged in the response to abiotic stress in Solanaceae plants. This eighteenth-amino-acid-long molecule was isolated from tomato leaves, where it is synthesized as a protein precursor-prosystemin (Coppola et al. 2015). Grafting experiments showed that, in tomato plants containing prosystemin transgene (transformed rootstock), a systemic signal responsible for production of high content of proteinase inhibitor in undamaged leaves (nontransformed scion) was present (McGurl et al. 1994). These findings proved the function of systemin as a mobile wound signal. It was reported in the other studies that both jasmonic acid and systemin were engaged in wound-induced salt stress tolerance in tomato plants (Orsini et al. 2010). The results showed that overexpression of prosystemin reduced of stomatal conductance. Nevertheless, transgenic tomato plants preserved a higher stomatal conductance in response to salt stress in comparison to nontransformed plants.

\section{Expansins}

Expansins (EXP) are a group of small proteins (25-27 kDa) found in plant cell walls. They are responsible for proper extension of the plant cell wall during plant growth causing wall stress relaxation and irreversible wall extension (Xu et al. 2014). Some data suggest that expansins may be important in regulating plant tolerance to a variety of abiotic stresses (Gao et al. 2010; Xu et al. 2014). Overproduction of the expansin gene TaEXPB23 in transgenic tobacco promoted drought tolerance (Li et al. 2011). Overexpression of the expansin coding sequence CsExpl from cucumber in transgenic tomato plants caused complex changes of their appearance (mature plants characterized by dwarfish, shortened internodes and leaves) in comparison to WT plants. Dark-grown seedlings displayed altered (short and wide) hypocotyl (Rochange et al. 2001). Furthermore, transgenic plants overexpressing CsExpl displayed impairment under salt and ABA stress. These findings suggest that this group of proteins affect cell wall organisation 
under stress conditions and therefore helps plants adapt to unfavourable environments.

\section{Modifications of protein potentially involved in abiotic stress tolerance}

Genetic modifications aiming at obtaining stress-tolerant crops are based on regulation or transfer of various genes which products are engaged in stress response and tolerance. Among them LEA proteins (Late Embryogenesis Abundance) or signal transduction proteins can be found (Goel et al. 2011; Muñoz-Mayor et al. 2012; ÁlvarezViveros et al. 2013).

LEA proteins, abundantly occurred due to osmotic stress or desiccation, are involved in many actions including prevention of membrane leakage, membrane and protein stabilisation, protection of cytosolic structures, maintenance of water balance and ion sequestration (Olvera-Carrillo et al. 2011). It has been proved that a novel class of LEA in plants is involved in freezing tolerance (Sasaki et al. 2014). Common characteristics of this group of proteins generally include hyper hydrophilicity, heat stability, internally disordered and transcriptionally regulated and ABA-responsive gene expression (Sasaki et al. 2014). With respect to amino acid sequences, LEA proteins were divided into several classes (Olvera-Carrillo et al. 2011). One of them are dehydrins (DHNs), which additionally possess chaperone-like and detergent properties. LEA genes have been genetically modified in many crop plants in order to enhance tolerance to drought or salt stress. It was reported that tomato plants with overproduction of a dehydrin, (from tas14 gene), acquired higher long-term tolerance to salinity and drought stress. Moreover, constitutive expression of this gene did not impact plant growth under normal conditions (MuñozMayor et al. 2012). This is a desirable feature, since the constitutive overexpression of most stress-associated genes has adverse influence on growth and yield of plants under normal condition. Additionally, under salinity, the plants overexpressing the tas 14 gene are able to transport $\mathrm{Na}^{+}$ ions between young and old leaves, a feature that is closely associated with resistance to the action of a hydrochloric stressor. It also should be emphasised that the aforementioned tolerance is strictly correlated with the capability of plants to quickly elevate ABA production after they detect dehydration. Other studies considering adaptation of plants to stress conditions clearly pointed out the pleiotropic effect of ShDHN under cold stress (Liu et al. 2015). It has been shown that, in comparison to the sensitive $S$. lycopersicum, the overexpression of the $S h D H N$ gene (originating from wild tomato species $S$. habrochaites) in the cold-tolerant $S$. habrochaites was adjusted by exogenous signalling molecules and other abiotic stresses including osmotic, salt, drought ones. Therefore, overexpression of $S h D H N$ in tomato plants significantly improves tolerance to the aforementioned types of abiotic stresses. Overexpression of $S h D H N$ gene affected expression of antioxidant enzymes and hence was also responsible for the reduction of the level of ROS under cold conditions. Additionally, it triggered expression a few genes engaged into jasmonate signalling pathway and ROS scavenging.

Another target to be modified while working on plant tolerance are signal transduction proteins e.g. kinases (Mishra et al. 2012; $\mathrm{Li}$ et al. 2013). The mitogen-activated protein kinases (MAPKs) are known to play a crucial role in tolerance-related signaling networks correlated with different stress conditions (e.g. drought stress) (Huang et al. 2012). It was proved that SpMPKs (the MAPKs from Solanum pimpinellifolium) genes significantly improved drought tolerance of tomato lines. Li et al. (2016) reported that overexpression of SIMPK7 was positively correlated with improved tolerance of tomato to chilling stress. Another multigene plant characteristic family are the calciumdependent protein kinases (CDPKs) which like MAPKs are engaged in responses to a broad range of abiotic stresses (Gao et al. 2014). For example, the expression of LeCRKI gene-an isoform of $\mathrm{Ca}^{2+}$-dependent protein kinase, is stimulated by different factors such as salicylic acid, ethylene and also mechanical injury and cold (Leclercq et al. 2005). Recently it has been reported that MdSOS $2 L 1$ (an apple derived CIPK kinase) had positive impact on salt tolerance both in tomato and apple by increasing the level of antioxidant metabolites (Hu et al. 2015b).

\section{Conclusions}

It is beyond doubt that abiotic stresses adversely influence crop yield affecting growth, development and productivity. They cause disorders at all levels of plant organization and, when extreme, may cause death. However, plants have powerful mechanisms to counteract stress - the ability of adaptation. Elucidation of the mechanism of tolerance at biochemical, physiological and morphological levels remains one of the greatest challenges facing contemporary plant physiology. On the bases of the knowledge concerning adaptive strategies and components involved, putative genetic targets for enhancing crop stress tolerance have been determined and some examples of their use are presented in this paper. At the cellular level, the target molecules and pathways to be modified can be found among those involved in responses of the membrane system, cell wall architecture, adjustments of the cell cycle and division, and in synthesis and metabolism of endogenous molecules. They can be found among structural and functional proteins as well, including stress tolerance proteins (such as LEA, 
late embryogenesis abundant proteins or chaperones) and stress response proteins. As it presented, the modifications of the genes behind these processes have allowed plants displaying increased tolerance to abiotic stresses to be produced (Yu et al. 2009; Khare et al. 2010; Muñoz-Mayor et al. 2012). The use of genetic engineering made further research on enhancement of plant tolerance possible, even when conventional breeding reached its limits. Molecular biology techniques allow to introduce precise gene changes without eliminating native genetic traits at the same time, which might be the case during traditional field or pure in vitro screening. Also their time effectiveness and applicability to a wide range of species are among their obvious advantages (Gerszberg et al. 2015). However, there are some questions regarding research on genetically induced tolerance as well, since the abiotic stresses are in a way interrelated in their nature and they usually affect plants almost simultaneously. Consequently, it would perhaps be justified to develop a more multi-target strategy for changing plant responses, instead of focusing on a single genetic event (affecting one separate function). Here, the engineering of genes encoding transcription factors involved in the regulation of stress-responsive genes seems to be the strategy of choice. Not only the multidirectional activity of the transcription factors can be used, but also their overexpression connected with simultaneous modifications of other target sequences (e.g. genes of mannitol synthesis and accumulation pathways of). Such an approach would probably also address the objection of the limited effectiveness observed when only a single modification (not referring to TFs) was introduced. However, no matter how effective the genetic strategies would be, there is one drawback very difficult to overcome, its genetic character. Although transgenic crops are subject to much stricter safety tests and regulations before sale to the market in comparison to nontransgenic crops, they are being questioned in many parts of the world raising strong public concerns (Eisenstein 2013; Chow et al. 2016; Smart et al. 2016). In this field, alternative methods, such as conventional breeding, in vitro screening or Molecular Marker Assisted Breeding (MAS) can be used. Among them, MAS, supported by phenomics, is a particularly promising approach for this kind of crop improvement (Ashraf et al. 2012). It was widely studied in different crop species (Jiang 2013) proving its superiority over conventional breeding and in vitro screening. The confirmed presence of the molecular marker, here a desired gene involved in stress tolerance, assures that plants with desirable profiles are investigated from the early stages of research. Moreover, the important advantage is the possibility of MAS application regardless of the stage of development of the tested plants. Unfortunately, it also has some potential drawbacks such as: high costs of implementation, modifications of traits presented only in a given crop species or the limited effectiveness in the case of crops having long generation times. In this context, genetic engineering of "tolerance sequences" appeared to be much more precise and displaying much wider spectrum of action. Moreover, as opposed to the competitive methods, most of its weaknesses can be minimized or overcome.

Acknowledgements The Authors would like to thank Professor Kononowicz A.K. (University of Lodz), for the scientific and editorial comments the manuscript. This work was supported by University of Lodz (research fund B1511000000201.01).

Authors contributions AG designed the outline of the article and wrote the manuscript. KHK composed figure. AG, KHK reviewed recent literature on the topic as well as provided scientific feedback. All authors read and approved the manuscript.

Open Access This article is distributed under the terms of the Creative Commons Attribution 4.0 International License (http:// creativecommons.org/licenses/by/4.0/), which permits unrestricted use, distribution, and reproduction in any medium, provided you give appropriate credit to the original author(s) and the source, provide a link to the Creative Commons license, and indicate if changes were made.

\section{References}

Abu-El-Heba GA, Hussein GM, Abdalla NA (2008) A rapid and efficient tomato regeneration and transformation system. Agric For Res 58: 103-110. http://d-nb.info/101025801X/34

Alćazar R, Altabella T, Marco F, Bortolotti C, Reymond M, Koncz C, Carrasco, Tiburcio AF (2010) Polyamines: molecules with regulatory functions in plant abiotic stress tolerance. Planta 231:1237-1249. doi:10.10007/s00425-010-1130-0

Álvarez-Viveros MF, Inostroza-Blancheteau C, Timmermann T, González M, Arce-Johnson P (2013) Overexpression of GlyI and GlyII genes in transgenic tomato (Solanum lycopersicum Mill.) plants confers salt tolerance by decreasing oxidative stress. Mol Biol Rep 4:3281-3290. doi:10.1007/ s11033-012-2403-4

Al-Whaibi HM (2011) Plant heat-shock proteins: A mini review. J King Saud Univ-Sci 23:139-150. doi:10.1016/j. jksus.2010.06.022

Apel W, Bock R (2009) Enhancement of carotenoid biosynthesis in transplastomic tomatoes by induced lycopene-to-provitamin A conversion. Plant Physiol 1:59-66. doi:10.1104/pp.109.140533

Ashraf MA, Akram NA, Mehboob-ur-Rahman, Foolad MR (2012) Marker-Assisted Selection in plant breeding for salinity tolerance. Methods Mol Biol 913:305-333. doi:10.1007/978-1-61779-986-0_21

Aydin S, Büyük I, Aras ES (2014) Expression of SOD gene and evaluating its role in stress tolerance in $\mathrm{NaCl}$ and PEG stressed Lycopersicum esculentum. Turk J Bot 38:89-98. doi:10.3906/ bot-1305-1

Baranova EN, Serenko EK, Balachnina TI, Kosobruhov AA, Kurenina LV, Gulevich AA, Maisuryan AN (2010) Activity of the photosynthetic apparatus and antioxidant enzymes in leaves of transgenic Solanum lycopersicum and Nicotiana tabacum plants, with FeSOD1 gene. Russ Agr Sci 36(4) 242-249. doi:10.3103/ S1068367410040075 
Baranova YN, Akanov EN, Gulevich AA, Kurenina LV, Danilova SA, Khaliluev MR (2014) Dark respiration rate of transgenic tomato plants expressing FeSOD1 gene under chloride and sulfate salinity. Russ Agr Sci 1:14-17. doi:10.3103/S1068367414010029

Bhaskaran S, Savithramma DL (2011) Co-expression of Pennisetum glaucum vacuolar $\mathrm{Na}^{+} / \mathrm{H}^{+}$antiporter and Arabidopsis $\mathrm{H}^{+}$-pyrophosphatase enhances salt tolerance in transgenic tomato. J Exp Bot 15:5561-5570. doi:10.1093/jxb/err237

Briza JD, Pavingerova P, Prikrylova J, Gazdova J, Vlasak J, Niedermeirova $H$ (2008) Use of phosphomannose isomerise- based selection system for Agrobacterium-mediated transformation of tomato and potato. Biol Plant 52:453-461. doi:10.1007/ s1053-008-0090-8

Chaudhry Z, Rashid H (2010) An improved Agrobacterium-mediated transformation in tomato using hygromycin as a selective agent. Afr J Biotechnol 9:1882-1891

Chen THH, Murata N (2011) Glycinebetaine protects plants against abiotic stress: mechanisms and biotechnological applications. Plant Cell Environ 34:1-20. doi:10.1111/j.1365-3040.2010.02232.x

Cheng L, Zou Y, Ding S, Zhang J, Yu X, Cao J, Lu G (2009) Polyamine accumulation in transgenic tomato enhances the tolerance to high temperature stress. J Integr Plant Biol 5:489-499. doi:10.1111/j.1744-7909.2009.00816.x

Chetty VJ, Ceballos N, Garcia D, Narvaez-Vasquez J, Lopez W, Orozco-Cardenas ML (2013) Evaluation of four Agrobacterium tumefaciens strains for the genetic transformation of tomato (Solanum lycopersicum L.) cultivar Micro-Tom. Plant Cell Rep 32:239-247. doi:10.1007/s00299-012-1358-1

Chow S, Norris JF, Bilder, B (2016) Insight into the genetically modified foods: from the concerns of safety to food development (part I). Sci Insigt. doi:10.15354/si.16.vi010

Coppola M, Corrado G, Coppola V, Cascone P, Martinelli R, Digilio MC, Pennacchio F, Rao R (2015) Prosystemin overexpression in tomato enhances resistance to different biotic stresses by activating genes of multiple signaling pathways. Plant Mol Biol Rep 33:1270-1285. doi:10.1007/s11105-014-0834-x

Cortina C, Culianez-Macia FA (2004) Tomato transformation and transgenic plant production. Plant Cell Tiss Org Cult 76:269-275

Cortina C, Culianez-Macia FA (2005) Tomato abiotic stress enhanced tolerance by trehalose biosynthesis. Plant Sci 169:75-82. doi:10.1016/j.plantsci.2005.02.026

Cruz-Mendivil A, Rivera-Lopez J, German-Baez LJ, Lopez-Meyer M, Hernandez-Verdugo S, Lopez-Valenzuela JA, Reyes-Moreno C, Valdez-Ortiz A (2011) A simple and efficient protocol for plant regeneration and genetic transformation of tomato cv. Micro-Tom from leaf explants. Hortscience 46(12):1655-1660

Cueno MC, Hibi Y, Karamatsu K, Yasutomi Y, Imai K, Laurena AC, Okamoto T (2010) Preferential expression and immunogenicity of HIV-1 Tatfusion protein expressed in tomato plant. Transgenic Res 19:889-895. doi:10.1007/s11248-009-9358-9

D'Ambrosio C, Stigliani AL, Giorio G (2011) Overexpression of CrtR-b2 (carotene beta hydroxylase 2) from S. lycopersicum L. differentially affects xanthophylls synthesis and accumulation in transgenic tomato plants. Transgenic Res 20:47-60. doi:10.1007/s11248-010-9387-4

Da Silva GJ, de Oliveira AC (2014) Genes acting on transcriptional control during abiotic stress responses. Adv Agr. doi: $10.1155 / 2014 / 587070$

De Guzman G, Walmsley AM, Webster D, Hamill JD (2011) Hairy roots cultures from different Solanaceous species have varying capacities to produce $E$. coli $\mathrm{B}$-subunit heat-labile toxin antigen. Biotechnol Lett 33:2495-2502

Dominguez T, Hernandez L M, Pennycooke JC, Jimenez P, Martınez-Rivas JM, Sanz C, Stockinger EJ, Sanchez-Serrano
JJ, Sanmartin M (2010) Increasing v-3 desaturase expression in tomato results in altered aroma profile and enhanced resistance to cold stress. Plant Physiol 153:655-665. doi:10.1104/ pp. 110.154815

Dong QL, Wang CR, Liu DD, Hu DG, Fang MJ, You CX, Yao YX, Hao YJ (2013) MdVHA-A encodes an apple subunit A of vacuolar H+-ATPase and enhances drought tolerance in transgenic tobacco seedlings. J Plant Physiol 170:601-609. 10.1016/j.jplph.2012.12.014

Duan M, Feng HL, Wang LY, Li D, Meng QW (2012) Overexpression of thylakoidal ascorbate peroxidase shows enhanced resistance to chilling stress in tomato. J Plant Physiol 169:867-877. doi:10.1016/j.jplph.2012.02.012

Eisenstein M (2013) Discoveryinadryspell. Nature 501:S7-S9. doi:10.1038/501S7a

El-Siddig MA, El-Hussein AA, Saker MM (2011) Agrobacteriummediated transformation of tomato plants expressing defensin gene. Int J Agr Res 4:323-334. doi:10.3923/ijar.2011.323.334

FAOSTAT (2013). http://faostat3.fao.org/home/E

Fernandez AI, Viron N, Alghadow M, Karimi M, Jones M, Amsellem Z, Sicard A, Czerednik A, Angenent G, Grierson D, May S, Seymour G, Eshed Y, Lemaire-Chamley M, Rothan C, Hilson P (2009) Flexible tools for gene expression and silencing in tomato. Plant Physiol 4:1729-1740 doi:10.1104/ pp. 109.147546

Fernandez-Moreno JP, Orzaez D, Granell A (2013) VIGS: A tool to study fruit development in Solanum lycopersicum. Methods Mol Biol 975:183-196. doi:10.1007/978-1-62703-278-0_14

Foolad MR (2007) Genome mapping and molecular breeding of tomato. Int J Plant Genom. doi:10.1155/2007/64358

Fuentes AD, Ramos PL, Sanchez Y, Callard D, Ferreira A, Tiel K, Cobas K, Rodriguez R, Borroto C, Doreste V, Pujol M (2008) A transformation procedure for recalcitrant tomato by addressing transgenic plant-recovery limiting factors. Biotechnol J 3:10881093. doi:10.1002/biot.200700187

Gao X, Cox KL Jr, He P (2014) Functions of calcium-dependent protein kinases in plant innate immunity. Plants 3:160-176. doi:10.3390/plants3010160

Gao N, Shen W, Cao Y, Su Y, Shi W (2009) Influence of bacterial density during preculture on Agrobacterium-mediated transformation of tomato. Plant Cell Tiss Org Cult 98:321-330. doi:10.1007/s11240-009-9566-2

Gao X, Liu K, Lu YT (2010) Specific Roles of AtEXPA1 in plant growth and stress adaptation. Russ J Plant Physiol 57:254-259. doi: $10.1134 /$ S1021443710020111

Garcia-Abellan JO, Egea I, Pineda B, Sanchez-Bela P, Belver A, Garcia-Sogo B, Flores FB, Atares A, Moreno V, Bolarin MC (2014) Heterologous expression of the yeast HAL5 gene in tomato enhances salt tolerance by reducing shoot $\mathrm{Na}^{+}$accumulation in the long term. Physiol Plantarum 152:700-713. doi:10.1111/ppl.12217

Gerszberg A, Wiktorek-Smagur A, Hnatuszko-Konka K, Łuchniak P, Kononowicz AK (2012) Expression of recombinant staphylokinase, a fibrin-specific plasminogen activator of bacterial origin, in potato (Solanum tuberosum L.) plants. World J Microbiol Biotechnol 28:1115-1123. doi:10.1007/s11274-011-0912-2

Gerszberg A, Hnatuszko-Konka K, Kowalczyk T, Kononowicz AKK (2015) Tomato (Solanum lycopersicum L.) in the service of biotechnology. Plant Cell Tiss Org Cult 120:881-902. doi:10.1007/ s11240-014-0664-4

Giri J (2011) Glycinebetaine and abiotic stress tolerance in plants. Plant Signal Beh 6(11):1746-1751. doi:10.4161/psb.6.11.17801

Gisbert C, Rus AM, Boların C M, Lopez-Coronado JM, Arrillaga I, Montesinos C, Caro M, Serrano R, Moreno V (2000) The yeast HAL1 gene improves salt tolerance of transgenic tomato. Plant Physiol 123:393-402 doi: doi:10.1104/pp.123.1.393 
Glick BR, Todorovic B, Czarny J, Cheng Z, Duan J, McConkey B (2007) Promotion of plant growth by bacterial ACC deaminase. Cr Rev. Plant Sci 26:227-242. 10.1080/07352680701572966

Goel D, Singh AK, Yadav V, Babbar SB, Bansal KC (2010) Overexpression of osmotin gene confers tolerance to salt and drought stresses in transgenic tomato (Solanum lycopersicum L.). Protoplasma 245:133-141. doi:10.1007/s00709-010-0158-0

Goel D, Singh AK, Yadav V, Babbar SB, Murata N, Bansal KC (2011) Transformation of tomato with a bacterial coda gene enhances tolerance to salt and water stresses. J Plant Physiol 11:1286-1294. doi:10.1016/j.jplph.2011.01.010

Gong B, Wang X, Wei M, Yang F, Li Y, Shi Q (2015) Overexpression of S-adenosylmethionine synthetase 1 enhances tomato callus tolerance to alkali stress through polyamine and hydrogen peroxide cross-linked networks. Plant Cell Tiss Organ Cult. doi:10.1007/s11240-015-0901-5

Grichko VP, Glick BR (2001) Amelioration of flooding stress by ACC deaminase-containing plant growth-promoting bacteria. Plant Physiol Biochem 39:11-17. doi:10.1016/ S0981-9428(00)01212-2

Guo M, Zhang YL, Meng ZJ, Jiang J (2012) Optimization of factors affecting Agrobacterium-mediated transformation of MicroTom tomatoes. Genet Mol Res 1:661-671. doi:10.4238/2012

Gupta S, Rashotte AM (2014) Expression patterns and regulation of SlCRF3 and SlCRF5 in response to cytokinin and abiotic stresses in tomato (Solanum lycopersicum). J Plant Physiol 171:349-358. doi:10.1016/j.jplph.2013.09.003

Gururani MA, Tapan Mohanta K, Bae H (2015) Current understanding of the interplay between phytohormones and photosynthesis under environmental stress. Int J Mol Sci 16:19055-19085. doi:10.3390/ijms 160819055

Hasan M, Khan AJ, Khan S S, Shah AH, Khan AR, Mirza B (2008) Transformation of tomato (Lycopesricon esculentum Mill.) with Arabidopsis early flowering gene APETALI (API) Through Agrobacterium infiltration of ripened fruits. Pak J Bot $1: 161-173$

Herbette S, Le Menn A, Rousselle P, Ameglio T, Faltin Z, Branlard G, Eshdatd Y, Julien JL, Drevet JR, Roeckel-Drevet P (2005) Modification of photosynthetic regulation in tomato overexpressing glutathione peroxidase. Biochim Biophys Acta 1724:108-118. doi:10.1016/j.bbagen.2005.04.018

Herbette S, Tourvieille de Labrouheb D, Drevet JR, Roeckel-Drevet P (2011) Transgenic tomatoes showing higher glutathione peroxydase antioxidant activity are more resistant to an abiotic stress but more susceptible to biotic stresses. Plant Sci 180:548553. doi:10.1016/j.plantsci.2010.12.002

Hnatuszko-Konka K, Kowalczk T, Gerszberg A, Wiktorek-Smagur A, Kononowicz AK (2014) Phaseolus vulgaris-Recalcitrant potential. Biotech Adv 32:1205-1215. 10.1016/j. biotechadv.2014.06.001

Hossain MA, Piyatida P, Teixeira da Silva JA, Fujita M (2012) Molecular mechanism of heavy metal toxicity and tolerance in plants: central role of glutathione in detoxification of reactive oxygen species and methylglyoxal and in heavy metal chelation. J Bot. doi: $10.1155 / 2012 / 87287$

Hsieh TH, Lee JT, Yang PT, Chiu LH, Charng YY, Wang YC, Chan MT (2002) Heterology expression of the Arabidopsis C-Repeat/Dehydration Response Element Binding Factor 1 gene confers elevated tolerance to chilling and oxidative stresses in transgenic tomato. Plant Physiol 129:1086-1094

Hsieh TH, Li CW, Su RC, Cheng CP, Sanjaya, Tsai YC, Chan MT (2010) A tomato bZIP transcription factor, SlAREB, is involved in water deficit and salt stress response. Planta 231:1459-1473. doi:10.1007/s00425-010-1147-4

Hu DG, Wang SH, Luo H, Ma QJ, Yao YX, You CX, Hao YJ (2012) Overexpression of MdVHA-B, a V-ATPase gene from apple, confers tolerance to drought in transgenic tomato. Sci Hort 145:94-101. 10.1016/j.scienta.2012.08.010

Hu Y, Wu Q, Sprague SA, Park J, Oh M, Rajashekar CB, Koiwa H, Nakata PA, Cheng N, Hirschi KD, Frank F White FF, Park S (2015a) Tomato expressing Arabidopsis glutaredoxin gene AtGRXS17 confers tolerance to chilling stress via modulating cold responsive components. Hort Res 2:15051. doi:10.1038/ hortres.2015.51

Hu DG, Ma QJ, Sun CH, Sun MH, You CX, Hao YJ (2015b) Overexpression of MdSOS2L1, a CIPK protein kinase, increases the antioxidant metabolites to enhance salt tolerance in apple and tomato. Physiol Plant 156:201-214. doi:10.1111/ ppl12354.

Huang Z, Zhang Z, Zhang X, Zhang H, Huang D, Huang R (2004) Tomato TERF1 modulates ethylene response and enhances osmotic stress tolerance by activating expression of downstream genes. FEBS Lett 573:110-116. doi:10.1016/j. febslet.2004.07.064

Huang GT, Ma SL, Bai LP, Zhang L, Ma H, Jia P, Liu J, Zhong M, Guo ZF (2012) Signal transduction during cold, salt, and drought stresses in plants. Mol Biol Rep 39:969-987. doi:10.1007/s11033-011-0823-1

Huertas R, Rubio L, Cagnac O, Garcia-Schanchez MJ, De Dios Alche J, Venema K, Fernandez JA, Rodriguez-Rosales MP (2013) The $\mathrm{K}+\mathrm{H}+$ antiporter LeNHX2 increases salt tolerance by improving $\mathrm{K}+$ homeostasis in transgenic tomato. Plant Cell Environ 36:2135-2149. doi:10.1111/pce.12109

Islam A, Chowdhury J, Seraj ZI (2010) Establishment of optimal conditions for an Agrobacterium mediated transformation in four tomato (Lycopersicon esculentum Mill.) varieties grown in Bangladesh. J Bangladesh Acad Sci 34(2):171-179. 10.3329/ jbas.v34i2.6863

Jaberolansar N, Hayati J, Rajabi-Memari H, Hosseini-Tafreshi SA, Nabati-Ahmadi D (2010) Tomato and tobacco phytoene desaturase gene silencing by virus-induced gene silencing (VIGS) technique. Iran J Virol 1:7-11

Janani C, Girija S, Ranjitha Kumari BD (2013) In vitro culture and Agrobacterium-mediated transformation in high altitude tomato (Lycopersicon esculentum Mill.) cultivar Shalimar. Int J Pharm Teach Pract 4(1):483-488. http://iomcworld.com/ijptp/files/ Rajitha\%20Kumari\%20March\%202013.pdf

Jiang GL (2013) Molecular markers and marker-assisted breeding in plants, plant breeding from laboratories to fields. In: Andersen SB (ed) Plant breeding from laboratories to fields InTech, Rijeka. doi:10.5772/52583.

Kadyrzhanova DK, Vlachonasios KE, Ververidis P, Dilley DR (1998) Molecular cloning of a novel heat induced/chilling tolerance related cDNA1 in tomato fruit by use of mRNA differential display. Plant Mol Biol 36:885-895. doi:10.102 3/A:1005954909011

Kaur P, Bansal KC (2010) Efficient production of transgenic tomatoes via Agrobacterium-mediated transformation. Biol Plantarum 54:344-348. doi:10.1007/s10535-010-0060-9

Khare N, Goyary D, Kumar Singh N, Shah P, Rathore M, Anandhan S, Sharma D, Arif M, Ahmed Z (2010) Transgenic tomato cv. Pusa Uphar expressing a bacterial mannitol-1-phosphate dehydrogenase gene confers abiotic stress tolerance. Plant Cell Tiss Organ Cult 103:267-277. doi:10.1007/s11240-010-9776-7

Khoudi H, Nouri-Khemakhem A, Gouiaa S, Masmoudi K (2009) Optimization of regeneration and transformation parameters in tomato and improvement of its salinity and drought tolerance. Afr J Biotechnol 22: 6068-6076

Kissoudis C, Chowdhury R, van Heusden S, van de Wiel C, Finkers R, Visser RGF, Bai Y, van der Linden G (2015) Combined biotic and abiotic stress resistance in tomato. Euphytica 202:317-332. doi:10.1007/s10681-015-1363-x 
Klay I, Pirrello J, Riahi L, Bernadac A, Cherif A, Bouzayen M, Bouzid S (2014) Ethylene response factor Sl-ERF.B.3 is responsive to abiotic stresses and mediates salt and cold stress response regulation in tomato. Scientific World J 2014:12. doi:10.1155/2014/167681

Koul B, Sirivastava S, Vijay Amla D, Sanyal I (2014) Establishment and optimization of Agrobacterium-mediated transformation and regeneration of tomato (Solanum lycopersicum $\mathbf{L}$.) Int $\mathbf{J}$ Biosci 10:51-69. doi:10.12692/ijb/4.10.51-69

Labate JA, Robertson LD (2012) Evidence of cryptic introgression in tomato (Solanum lycopersicum L.) based on wild tomato species alleles. BMC Plant Biol 12:133. http://www.biomedcentral. com/1471-2229/12/133

Leclercq J, Ranty B, Sanchez-Ballesta MT, Li Z, Jones B, Jauneau A, Pech JC, Latche' A, Ranjeva R, Bouzayen M (2005) Molecular and biochemical characterization of LeCRK1, a ripeningassociated tomato CDPK-related kinase. J Exp Bot 409:25-35. doi:10.1093/jxb/eri003

Leidi EO, Barragan V, Rubio L, El-Hamdaoui A, Ruiz TM, Cubero B, Fernandez JA, Bressan RA, Hasegawa PH, Quintero FJ, Pardo JM (2010) The AtNHX1 exchanger mediates potassium compartmentation in vacuoles of transgenic tomato. Plant J 61:495506. doi:10.1111/j.1365-313X.2009.04073.x

Li F, Xinga S, Guoa Q, Zhaoa M, Zhanga J, Gaoa Q, Wangb G, Wanga W (2011) Drought tolerance through over-expression of the expansin gene TaEXPB23 intransgenic tobacco. J Plant Physiol 168:960-966. doi:10.1016/j.jplph.2010.11.023

Li C, Yan JM, Li YZ, Zhang ZC, Wang QL, Liang Y (2013) Silencing the $S p M P K 1, S p M P K 2$, and $S p M P K 3$ genes in tomato reduces abscisic acid-mediated drought tolerance. Int $\mathrm{J}$ Mol Sci 14:21983-21996. doi:10.3390/ijms 141121983

Li G, Santoni V, Maurel C (2014) Plant aquaporins: roles in plant physiology. Biochim Biophys Acta 1840:1574-1582. doi:10.1016/j.bbagen.2013.11.004

Li JB, Luan YS, Liu Z (2015) SpWRKY1 mediates resistance to Phytophthora infestans and tolerance to salt and drought stress by modulating reactive oxygen species homeostasis and expression of defense-related genes in tomato. Plant Cell Tiss Organ Cult 123:67-81. doi:10.1007/s11240-015-0815-2

Li Y, Yan J, Yang Y, He L, Zhu W (2016) Enhanced tolerance to chilling stress in tomato by overexpression of a mitogen-activated protein kinase, SIMPK7. Plant Mol Biol Rep 34:76-88. doi:10.1007/s11105-015-0897-3

Lichtenthaler HK (1988) In vivo chlorophyll fluorescence as a tool for stress detection in plants. In: Lichtenthaler HK (ed) Applications of chlorophyll fluorescence. Kluwer Academic Publishers, Dordrecht, p 129-142

Liu X, Yang JH, Li B, Yang XM, Meng QW (2010) Antisense expression of tomato chloroplast omega-3 fatty acid desaturase gene (LeFAD7) enhances the tomato high-temperature tolerance through reductions of trienoic fatty acids and alterations of physiological parameters. Photosyntheyhica 1:59-66. doi:10.1007/s11099-010-0009-4

Liu XY, Teng YB, Meng QW (2013) Enhancement of low-temperature tolerance in transgenic tomato plants overexpressing Lefad7 through regulation of trienoic fatty acids. Photosyntheyhica 2: 238-244. doi:10.1007/s11099-013-0014-5

Liu H, Yu C, Li H, Ouyang B, Wang T, Zhang J, Wang X, Ye Z (2015) Overexpression of ShDHN, a dehydrin gene from Solanum habrochaites enhances tolerance to multiple abiotic stresses in tomato. Plant Sci 231:198-211. 10.1016/j.plantsci.2014.12.006

Lorenzo O, Piqueras R, Sanchez-Serrano JJ (2003) Ethylene response factor integrates signals from ethylene jasmonate pathways in plant defense. Plant Cell 15:165-178 doi:10.1105/tpc.007468

Lyu JI, Min SR, Lee JH Lim YH, Kim JK, Bae CH, Liu JR (2013) Overexpression of a trehalose-6-phosphate synthase/ phosphatise fusion gene enhances tolerance and photosynthesis during drought and salt stress without growth aberrations in tomato. Plant Cell Tiss Organ Cult 112:257-262. doi:10.1007/s11240-012-0225-7

Mahesh U, Mamidala P, Rapolu S, Aragao FJL, Souza MT, Rao PJM, Kirti PB, Nanna RS (2013) Constitutive overexpression of small HSP24.4 gene in transgenic tomato conferring tolerance to high-temperature stress. Mol Breed 32:687-697. doi:10.1007/s11032-013-9901-5

McCormick S, Niedermeyer J, Fry J, Barnason A, Horsch R, Fraley R (1986) Leaf disc transformation of cultivated tomato ( $L$. esculentum) using Agrobacterium tumefaciens. Plant Cell Rep 2:81-84

McGurl B, Orozcoc-Ardenas M, Pearce G, Ryan CA (1994) Overexpression of the prosystemin gene in transgenic tomato plants generates a systemic signal that constitutively induces proteinase inhibitor synthesis. Proc Natl Acad Sci USA 21:9799-9802. doi:10.1073/pnas.91.21.9799

Meng X, Wang JR, Wang GD, Liang XQ, Li XD, Meng QW (2015) An $R 2 R 3-M Y B$ gene, LeAN2, positively regulated the thermotolerance in transgenic tomato. J Plant Physiol 175:1-8. doi:10.1016/j.jplph.2014.09.018

Metwali EMR, Soliman HIA, Fuller MP, Almaghrabi OA (2015) Improving fruit quality in tomato (Lycopersicum esculentum Mill) under heat stress by silencing the vis 1 gene using small interfering RNA technology. Plant Cell Tiss Organ Cult 121:153-166. doi:10.1007/s11240-014-0691-1

Minocha R, Majumdar R, Minocha SC (2014) Polyamines and abiotic stress in plants: a complex relationship. Front Plant Sci 5:1-17. doi:10.3389/fpls.2014.00175

Mishra SK, Tripp J, Winkelhaus S, Tschiersch B, Theres K, Nover L, Scharf KD (2002) In the complex family of heat stress transcription factors, HsfA1 has a unique role as master regulator of thermotolerance in tomato. Genes Dev 16:1555-1567. http://www.genesdev.org/cgi/doi/10.1101/gad.228802

Mishra KB, Ianacone R, Petrozza A, Mishra A, Armentano N, La Vecchia G, Trtilek M, Cellini F, Nedbal L (2012) Engineered drought tolerance in tomato plants is reflected in chlorophyll fluorescence emission. Plant Sci 182:79-86. doi:10.1016/j. plantsci.2011.03.022

Miura K, Shiba H, OhtaM, Seung Kang W, Sato A, Yuasa T, Iwaya-Inoue M, Kamada H, Ezura H (2012) SIICE1 encoding a MYC-type transcription factor controls cold tolerance in tomato, Solanum lycopersicum. Plant Biotechnol 29:253-260. doi:10.5511/plantbiotechnology.12.0303a

Moghaieb RE, Saneoka H, Fujita K (2004) Shoot regeneration from GUS-transformed tomato (Lycopersicon esculentum) hairy root. Cell Mol Biol Lett 3:439-449

Mohamed EA, Iwaki T, Munir I, Shigeoka S, Wadano A (2003) Overexpression of bacterial catalase in tomato leaf chloroplasts enhances photo-oxidative stress tolerance. Plant Cell Environ 26: 2037-2046. http://onlinelibrary.wiley.com/ doi/10.1046/j.0016-8025.2003.01121.x/pdf

Muñoz-Mayor MF, Pineda B, Garcia-Abellán JO, Antón T, GarciaSogo B, Sanchez-Bel P, Flores FB, Atarés A, Angosto T, Pintor-Toro JA, Moreno V, Bolarin MC (2012) Overexpression of dehydrin tas 14 gene improves the osmotic stress imposed by drought and salinity in tomato. J Plant Physiol 169:459-468. doi:10.1016/j.jplph.2011.11.018

Mustafiz A, Sahoo KK, Singla-Pareek SL, Sopory SK (2010) Metabolic engineering of glyoxalase pathway for enhancing stress tolerance in plants. In Ramanjulu S (ed) Plant stress tolerance, volume 639 of the series methods mol biol p 95-118. doi:10.1007/978-1-60761-702-0_6 
Nautiyal PC, Shono M, Egawa Y (2005) Enhanced thermotolerance of the vegetative part of MT-sHSP transgenic tomato line. Sci Hortic 105:393-409. doi:10.1016/j.scienta.2005.02.001

Noctor G, Mhamdi A, Chaouch S, Han Y, Neukermans J, MarquezGarcia B, Queval G, Foyer CH (2012) Glutathione in plants: an integrated overview. Plant Cell Environ 35:454-484. doi:10.1111/j.1365-3040.2011.02400.x

Olias R, Eljakaol Z, Li J, Alvarez deMorales P, Marin-Manzano C, Pardo JM, Belver A (2009) The plasma membrane Na+/H+ antiporter SOS1 is essential for salt tolerance in tomato and affects the partitioning of $\mathrm{Na}+$ between plant organs. Plant Cell Environ 32:904-916. doi:10.1111/j.1365-3040.2009.01971.x

Olvera-Carrillo Y, Reyes JL, Covarrubias AA (2011) Late embryogenesis abundant proteins. Plant Signal Behav 6(4):586-589. doi:10.4161/psb.6.4.15042

Orellana S, Yanez M, Espinoza A, Verdugo I, Gonzales E, Ruiz-Lara S, Cacaretto JA (2010) The transcription factor SIAREB1 confers drought, salt stress tolerance and regulates biotic and abiotic stress-related genes in tomato. Plant Cell Environ 33:21912208. doi:10.1111/j.1365-3040.2010.02220.xpc

Orsini F, Cascone P, De Pascalea S, Barbieri G, Corrado G, Rao R, Maggio A (2010) Systemin-dependent salinity tolerance in tomato: evidence of specific convergence of abiotic and biotic stress responses. Physiol Plantarum 138:10-21. doi:10.111 1/j.1399-3054.2009.01292.x2202191.0.2208

Orzaez D, Granell A (2009) Reverse genetics and transient gene expression in fleshy fruits. Plant Signal Behav 9:864-867. doi:10.1104/pp.109.13900

Orzaez D, Mirabel S, Wieland WH, Granell A (2006) Agroinjection of tomato fruits. A tool for rapid functional analysis of transgenes directly in fruit. Plant Physiol 1:3-11. doi:10.1104/ pp.105.068221

Pan IC, Li CW, Su RC, Cheng CP, Lin CS, Chan MT (2010) Ectopic expression of an EAR motif deletion mutant of SIERF3 enhances tolerance to salt stress and Ralstonia solanacearum in tomato. Planta 5:1075-1086

Pandey SK, Nookaraju A, Upadhyaya CP, Gururani MA, Venkatesh J, Kim DH, Park SW (2011) An update on biotechnological approaches for improving abiotic stress tolerance in tomato. Crop Sci 51:2303-2324

Paramesh H, Fakrudin, B, Kuruvinashetti, MS (2010) Genetic transformation of a local variety of tomato using gus gene: an efficient genetic transformation protocol for tomato. J Agric Technol 6:87-97. http://www.ijat-rmutto.com

Park EJ, Jenknic Z, Chen THH (2006) Exogenous application of glycinebetaine increases chilling tolerance in tomato plants. Plant Cell Physiol 6:706-714. doi:10.1093/pcp/pcj041

Park EJ, Jenknic Z, Pino MT, Murata N, Chen THH (2007) Glycinebetaine accumulation is more effective in chloroplasts than in the cytosol for protecting transgenic tomato plants against abiotic stress. Plant Cell Environ 30:994-1005. doi:10.1111/j.1365-3040.2007.01694.x

Patade VY, Khatri D, Kumari M, Grover A, Gupta SM, Ahmed Z (2013) Cold tolerance in osmotin transgenic tomato (Solanum lycopersicum L.) is associated with modulation in transcript abundance of stress responsive genes. SpringerPlus 2:117. doi:10.1186/2193-1801-2-117

Peres LEP, Morgante PG, Vecchi C, Kraus JE, Sluys MA (2001) Shoot regeneration capacity from roots and transgenic hairy roots of tomato cultivars and wild related species. Plant Cell Tiss Organ Cult 65:37-44. doi:10.1023/A:1010631731559

Pineda B, Garcia-Abellan JO, Perez F, Moyano E, Garcia Sogo B, Campos JF, Angosto T, Morales B, Capel J, Moreno V, Lozano R, Bolarin MC, Atares A (2012) Tomato: Genomic approaches for salt and drought stress tolerance. In Tuteja N, Gill SS, Tiburcio A, Tuteja R. (eds) Improving crop resistance to abiotic stress, Volume 1 \& Volume 2. WileyVCH Verlag GmbH\&Co. KGaA, Weinheim, Germany, doi:10.1002/9783527632930.ch43**

Qiu D, Diretto R, Tavarza G, Giuliano G (2007) Improved protocol for Agrobacterium mediated transformation of tomato and production transgenic plants containing carotenoid biosynthetic gene CsZCD. Sci Hort 112:172-175. doi:10.1016/j. scienta.2006.10.015

Rai GK, Prakash Rai N, Rathaur S, Kumar S, Singh M (2013a) Expression of $r d 29 A: \because A t D R E B 1 A / C B F 3$ in tomato alleviates drought-induced oxidative stress by regulating key enzymatic and non-enzymatic antioxidants. Plant Physiol Biochem 69:90-100. DOI:10.1016/j.plaphy.2013.05.002

Rai AC, Singh M, Shah K (2013b) Engineering drought tolerant tomato plants over-expressing BcZAT12 gene encoding a $\mathrm{C} 2 \mathrm{H} 2$ zinc finger transcription factor. Phytochemistry 85:44 50. 10.1016/j.phytochem.2012.09.007

Raiola A, Rigano MM, Calafiore R, Frusciante L, Barone A (2014) Enhancing the human-promoting effects of tomato fruit for biofortified food. Hindawi Publishing Corporation. Mediators Inflamm. doi:10.1155/2014/139873

Rehem BC, Zanelato Bertolde F, Furtado de Almeida AA (2012) Regulation of gene expression in response to abiotic stress in plants. In: Bubulya P (ed) Cell metabolism-cell homeostasis and stress response. InTech, Rijeka, doi:10.5772/26636, ISBN 978-953-307-978-3**

Rochange SF, Wenzel CL, McQueen-Mason SJ (2001) Impaired growth in transgenic plants over-expressing an expansin isoform. Plant Mol Biol 46:581-589. doi:10.102 3/A: 101065021700

Romero I, Tikunov Y, Bovy A (2011) Virus-induced gene silencing in detached tomatoes and biochemical effects of phytoene desaturase gene silencing. J Plant Physiol 168:1129-1135. doi:10.1016/j.jplph.2010.12.020

Ruf S, Bock R (2014) Plastid transformation in tomato. Methods Mol Biol 1132:265-276. doi:10.1007/978-1-62703-995-6_16

Ruma D, Dhaliwal MS, Kaur A, Gosal SS (2009) Transformation of tomato using biolistic gun for transient expression $\beta$ glucuronidase gene. Indian J Biotechnol 8:363-369. http:// nopr.niscair.res.in/bitstream/123456789/6151/1/IJBT\%20 $8 \% 284 \% 29 \% 20363-369$.pdf

Sabehat A, Weiss D, Lurie S (1996) The correlation between heatshock protein accumulation and persistence and chilling in tomato fruit. Plant Physiol 110:531-537

Sade N, Vinocur BJ, Diber A, Shatil A, Ronen G, Nissan H, Wallach R, Karchi H, Moshelion M (2009) Improving plant stress tolerance and yield production: is the tonoplast aquaporin SITIP2;2 a key to isohydric to anisohydric conversion? New Phytol 181:651-661. doi:10.1111/j.1469-8137.2008.02689.x

Sade N, Gebretsadik M, Seligmann R, Schwartz A, Wallach R, Moshelion M (2010) The role of tobacco aquaporin1 in improving water use efficiency, hydraulic conductivity, and yield production under salt stress. Plant Physiol 152: 245-254. http://www.plantphysiol.org/cgi/doi/10.1104/ pp. 109.145854

Safdar N, Mirza B (2014) An experimental comparison of different transformation procedures assessed in tomato cv. Rio Grande with yeast HAL 1 gene. Turk J Biochem 39(3):245-252. doi:10.5505/tjb.2014.86

Sahoo KS, Tripathi AK, Pareek A, Sopory SK, Singla-Pareek SL (2011) An improved protocol for efficient transformation and regeneration of diverse indica rice cultivars. Plant Methods 7:49. doi:10.1186/1746-4811-7-49

Sarkar AK, Lahiri A (2013) Specificity determinants for the abscisic acid response element. FEBS Open Bio 3:101-105. doi:10.1016/j.fob.2013.01.006 
Sasaki K, Christov NK, Tsuda S, Imai R (2014) Identification of a novel LEA protein involved in freezing tolerance in wheat. Plant Cell Physiol 55(1):136-147. doi:10.1093/pcp/pct164

Seong ES, Cho HS, Choi D, Joung YH, Lim CK, Hur JH, Wang MH (2007) Tomato plants overexpressing CaKR1 enhanced tolerance to salt and oxidative stress. Biochem Biophys Res Commun 363:983-988. doi:10.1016/j.bbrc.2007.09.104

Shah K, Singh M, Rai AC (2013) Effect of heat-shock induced oxidative stress is suppressed in BcZAT12 expressing drought tolerant tomato. Phytochemistry 95:109-117. 10.1016/j. phytochem.2013.07.026

Shah SH, Ali S, Jan SA, Din AU, Ali GM (2015) Piercing and incubation method of in planta transformation producing stable transgenic plants by overexpressing DREB1A gene in tomato (Solanum lycopersicum Mill.). Plant Cell Tiss Organ Cult 120:1139-1157. doi:10.1007/s11240-014-0670-6

Sharma MK, Solanke AU, Jani D, Singh Y, Sharma AK (2009) A simple and efficient Agrobacterium-mediated procedure for transformation of tomato. J Biosci 3:423-433

Shinozaki K, Yamaguchi-Shinozaki K (2007) Gene networks involved in drought stress response and tolerance. J Exp Bot 58:221-227. doi:10.1093/jxb/erl164

Singh S, Rathore M, Goyar D, Singh RK, Anandhan S, Sharma DK, Ahmed Z (2011) Induced ectopic expression of $A t-C B F 1$ in marker-free transgenic tomatoes confers enhanced chilling tolerance. Plant Cell Rep 30:1019-1028. doi:10.1007/ s00299-011-1007-0

Smart R, Blum M, Wesseler J (2016) Trends in approval times for genetically engineered crops in the United States and the European Union. J Agric Econ. doi:10.1111/1477-9552.12171

Sun HJ, Uchii S, Watanabe S, Ezura H (2006) A high efficient transformation protocol for Micro-Tom, a model cultivar for tomato functional genomics. Plant Cell Physiol 47:426-431. doi:10.1093/pcp/pci251

Sun S XP, Xing XJ, Xu XY, Cheng J, Zheng SW, Xing GM (2015) Agrobacterium-mediated transformation of tomato (Lycopersicon esculentum L. cv. Hezuo908) with improved efficiency. Biotechnol Biotechnol Equip 29(5):861-868. doi:10.1080/13102818.2015.10567

Thipyapong P, Melkonian J, Wolfe DW, Steffens JC (2004) Suppression of polyphenol oxidases increases stress tolerance in tomato. Plant Sci 167:693-703. doi:10.1016/j.plantsci.2004.04.008

Vannini C, Campa M, Iriti M, Genga A, Faoro F, Carravieri S, Rotino GL, Rossoni M, Spinardi A, Bracale M (2007) Evaluation of transgenic tomato plants ectopically expressing the rice Osmyb4 gene. Plant Sci 173:231-239. doi:10.1016/j. plantsci.2007.05.007

Vincour B, Altman A (2005) Recent advances in engineering plant tolerance to abiotic stress: achievements and limitations. Curr Opin Biotech 16:123-132. doi:10.1016/j.copbio.2005.02.001

Wang Y, Wisniewski M, Meilan R, Cui M, Fuchigami L (2006) Transgenic tomato (Lycopersicon esculentum) overexpressing cAPX exhibits enhanced tolerance to UV-B and heat stress. J App Hort 8:87-90. http://naldc.nal.usda.gov/download/23625/ PDF

Wang Y, Wisniewski M, Meilan R, Uratsu SL, Cui M, Dandekar A, Fuchigami L (2007) Ectopic expression of Mn-SOD in Lycopersicon esculentum leads to enhanced tolerance to salt and oxidative stress. J App Hort 9:3-8

Wang BQ, Zhang QF, Liu JH, Li GH (2011) Overexpression of PtADC confers enhanced dehydratation and drought tolerance in transgenic tobacco and tomato: effect on ROS elimination. Biochem Biophys Res Commn 413:10-16. doi:10.1016/j. bbrc.2011.08.015

Wang HS, Yu C, Tang XF, Zhu ZJ, Ma NN, Meng QW (2014) A tomato endoplasmic reticulum (ER)-type omega-3 fatty acid desaturase (LeFAD3) functions in early seedling tolerance to salinity stress. Plant Cell Rep 33:131-142. doi:10.1007/ s00299-013-1517-z

Wang T, Wen LW, Zhu HL (2015) Effectively organ-specific virus induced gene silencing in tomato plant. J Nature Sci 1:e34

Widoretno W, Perwitasari R, Arumingtyas EL, Utomo EUP, Wardiat $\mathrm{T}$ (2012) Genetic transformation of tomato (Lycopersicon esculentum Mill.) with Agrobacterium rhizogenes and production of 1ycopene in transformed root culture. Int Res. J Biotechnol 9:158-165. http://www.interesjournals.org/IRJOB

Wróblewski T, Tomczak A, Michelmore R (2005) Optimization of Agrobacterium-mediated transient assays of gene expression in lettuce, tomato, Arabidopsis. Plant Biotechnol J 2:259-273. doi:10.1111/j.1467-7652.2005.00123.x

Wu YF, Chen Y, Liang XM XZ (2006) An experimental assessment of the factors influencing Agrobacterium-mediated transformation in tomato. Russ J Plant Physiol 53:252-256. doi:10.1134/ S10214437060201666

Xu Q, Xu X, Shi Y, Xu J, Huang B (2014) Transgenic tobacco plants overexpressing a grass $P p E X P 1$ gene exhibit enhanced tolerance to heat stress. PLoS ONE doi:10.1371/journal.pone.0100792

Yamaguchi-Shinozaki K, Shinozaki K (2009) DREB regulons in abiotic-stress-responsive gene expression in plants. In Yamada $\mathrm{T}$, Spangenberg $\mathrm{G}$ (eds) Molecular breeding of forage and turf. The Proceedings of the 5 the international symposium. p 15-28. doi:10.1007/978-0-387-79144-9_2

Yanez M, Caseres S, Orellana S, Bastias A, Verdugo I, Luiz-Lara S, Casaretto JA (2009) An abiotic stress-responsive bZIP transcription factor from wild and cultivated tomatoes regulates stress-related genes. Plant Cell Rep 10:1497-1507. doi:10.1007/ s00299-009-0749-4

Yang S, Vanderbeld, Wan J, Huang Y (2010) Narrowing down the targets: towards successful genetic engineering of drought-tolerant crop. Mol Plant 3:469-490. doi:10.1093/mp/ssq016

Yang Y, Tang N, Xian Z, Li Z (2015) Two SnRK2 protein kinases genes play a negative regulatory role in the osmotic stress response in tomato. Plant Cell Tiss Organ Cult 122:421-434. doi:10.1007/s11240-015-0779-2

Yarra R, He SJ, Abbagani S, Ma B, Bulle M, Zhang WK (2012) Overexpression of wheat $\mathrm{Na}^{+} / \mathrm{H}^{+}$antiporter gene (TaNHX2) enhances tolerance to salt stress in transgenic tomato plants (Solanum lycopersicum L.). Plant Cell Tiss Organ Cult 111:49_ 57. doi:10.1007/s11240-012-0169-y

Yasmeen A, Mirza B, Inayatullah S, Safdar N, Jamil M, Ali S, Choudry MF (2009) In planta transformation of tomato. Plant Mol Biol Rep 27:20-28. doi:10.1007/s11105-008-0044-5

Yu C, Wang HS, Yang S, Tang XF, Duan M, Meng QW (2009) Overexpression of endoplasmic reticulum omega-3 fatty acid desaturase gene improves chilling tolerance in tomato. Plant Physiol Biochem 47:1102-1112. doi:10.1016/j.plaphy.2009.07.008

Zhang J, Hua H, Sun J, Li B, Zhu Q, Chen S, Zhang H (2012) Arabidopsis fatty acid desaturase FAD2 is required for salt tolerance during seed germination and early seedling growth. PLoS ONE 7(1):e30355. doi:10.1371/journal.pone.0030355

Zhang XH, Li B, Hu YG, Chen L, Min DH (2014) The wheat E subunit of V-Type H+-ATPase is involved in the plant response to osmotic. Stress Int J Mol Sci 15:16196-16210. doi:10.3390/ ijms 150916196

Zhao C, Mariko M, Sun A, Yi S, Li M, Liu J (2007) Constitutive expression of an endoplasmic reticulum small heat shock protein alleviates endoplasmic reticulum stress in transgenic tomato. J Plant Physiol 164:835-841. doi:10.1016/j. jplph.2006.06.004

Zhao C, Lang Z, Zhu JK (2015) Cold responsive gene transcription becomes more complex. Trends Plant Sci 20(8):466-468. doi:10.1016/j.tplants.2015.06.001 
Zhou F, Badillo-Corona JA, Karcher D, Gonzalez-Rabade N, Piepenburg K, Borchers AM, Maloney AP, Kavanagh TA, Gray JC, Bock R (2008) High-level expression of human immunodeficiency virus antigens from the tobacco and tomato plastid genomes. Plant Biotechnol J 9:897-913. doi:10.1111/j.1467-7652.2008.00356.x
Zhou T, Zhang H, Lai T, Qin C, Shi N, Wang H, Jin M, Zhong S, Fan Z, Liu Y, Wu Z, Jackson S, Giovannoni JJ, Rolin D, Gallusci P, Hong Y (2012) Virus-induced gene complementation reveals a transcription factor network in modulation of tomato fruit ripening. Sci Rep 2:836 doi:10.1038/srep00836 